\title{
Amino-Acid Ferroelectric Thin Films
}

\author{
Balashova E.V. and Krichevtsov B.B. \\ Ioffe Physico-technical Institute of RAS, St-Petersburg, \\ Russia
}

\section{Introduction}

The family of amino-acid ferroelectrics involves large number of crystals the chemical composition of which is based on combinations of different amino-acids (betaine $\left.\left(\mathrm{CH}_{3}\right)_{3} \mathrm{~N}^{+} \mathrm{CH}_{2} \mathrm{COO}-\right)$, sarcosine $\left(\mathrm{CH}_{3} \mathrm{NHCH}_{2} \mathrm{COOH}\right)$, glycine $\left.\left(\mathrm{H}_{2} \mathrm{NCH}_{2} \mathrm{COOH}\right)\right)$ and nonorganic acids $\left(\mathrm{H}_{3} \mathrm{PO}_{3}, \mathrm{H}_{3} \mathrm{AsO}_{4}, \mathrm{H}_{3} \mathrm{PO}_{4}, \mathrm{HCl}, \mathrm{H}_{2} \mathrm{SO}_{4}\right)$ or salts. The most well known example of amino-acid ferroelectrics - triglycine sulphate (TGS) - was discovered in 1956 (Matthias et al., 1956). After that the amino-acid ferroelectric crystals were synthesized on basis of sarcosine and in 80-th of the last century on basis of betaine amino-acids (Albers et al., 1988). The interest to betaine amino-acid ferroelectrics is concerned with large variety of phases (ferroelectric, ferroelastic, antiferroelectric, antiferrodistortive, incommensurate, glasslike state and so on), phase transformations, and with ferroelectric properties observed in these crystals. For example, a record value of dielectric constant at the ferroelectric phase transition $\varepsilon \approx 10^{6}$ has been observed in betaine arsenate crystals. Experimental and theoretical investigations of amino-acid ferroelectric single crystals has been carried out in large number of works and main results of these studies were summarized in review papers (Albers, 1988; Schaack, 1990).

Recently it was found (Balashova et al., 2008; 2011a) that thin films of betaine phosphite (BPI) and deuterated betaine phosphite (DBPI) can be manufactured by evaporation method on different substrates. The BPI films consist of large single-crystalline blocks and show ferroelectric properties mainly analogous to the bulk BPI crystals. The differences in dielectric behavior of films and bulk samples are related to film-substrate interaction and specifics of domain structure.

At present large attention is paid to ferroelectric thin films because of their potential applications in information storage systems, sensors of different fields, elements of microelectronics and so on (Tagantsev et al., 2010; Dawber et al. 2005; Ducharme et al. 2002). Also, the increased interest to multuferroic materials and, in particular, to composition of ferroelectrics and ferromagnets stimulates the search of ferroelectric films which can be prepared on different substrates without using high growth temperature. For these reasons the development and investigation of amino acide ferroelectric films seems to be of interest. In this chapter we present results of preparation and studies of BPI, DBPI and TGS films which were published or accepted for publication during last three years (Balashova et al., 2008; 2009a,b; 2010; 2011a,b).

The chapter is organized as follows: Section 2 is devoted to short description of structural and dielectric properties of some amino acid ferroelectric crystals which were used for 
preparation of films (TGS, BPI, DBPI); in Section 3 the growth method, preparation of substrates and geometry of obtained structures is described; in Section 4 the results of study of block and crystal structure of films are presented; Sections 5-9 are devoted to experimental investigations of low-signal and strong-signal dielectric response in BPI, DBPI, and TGS films grown on different substrates, calculations of dielectric permittivity of films, thermodynamic description of dielectric anomaly and modeling of dielectric hysteresis loops; Conclusions summarize main results of investigations.

\section{Amino-acid ferroelectric single crystals}

In this section we present short description of structural and some dielectric properties of bulk amino acid ferroelectric crystals (BPI, DBPI, TGS) which were used for preparation of films.

\subsection{TGS}

Triglycine sulfate (TGS) $\left(\mathrm{CH}_{2} \mathrm{NH}_{2} \mathrm{COOH}\right)_{3} \cdot \mathrm{H}_{2} \mathrm{SO}_{4}$, a ferroelectric discovered in 1956 (Matthias et al., 1956), displays a large pyroelectric coefficient and a high Volt/Watt sensitivity, and, thus, may be considered a unique material for pyroelectric uses (Lal \& Batra, 1993; Neumann, 1993). TGS undergoes second order phase transition from paraelectric to ferroelectric state at $T_{c}=322 \mathrm{~K}$ which is followed by change of structural space group of symmetry from $\mathrm{P} 22_{1} / \mathrm{m}$ to $\mathrm{P} 22_{1}$. TGS unit cell contains two formula units. Lattice parameters values of TGS at RT are $a=9.392 \AA, b=12.734 \AA, c=5.784 \AA$ and monoclinic angle $\beta=109.45^{\circ}$ (Fletcher, 1976). The phase transition results in (1) continuous reorientation of the $\mathrm{NH}^{+3}$ group of the glycine about the ac plane making it a statistically averaged mirror in the high-temperature paraelectric phase; (2) disordering of the proton that connects the glycine groups making the two glycine ions indistinguishable in the hightemperature paraelectric phase.

The phase transition of TGS in ferroelectric state is accompanied by appearance of spontaneous polarization $\mathrm{P}_{\mathrm{s}}$ along polar $\mathrm{b}$ axis and strong dielectric anomaly.

\subsection{Betaines (BPI, DBPI)}

Betaine phosphite (BPI), $\left(\mathrm{CH}_{3}\right)_{3} \mathrm{NCH}_{2} \mathrm{COO} \cdot \mathrm{H}_{3} \mathrm{PO}_{3}$, is a compound of betaine amino acid, $\left(\mathrm{CH}_{3}\right)_{3} \mathrm{~N}^{+} \mathrm{CH}_{2} \mathrm{COO}$-, and inorganic acid $\mathrm{H}_{3} \mathrm{PO}_{3}$. Ferroelectricity in BPI was discovered by Albers et al. (Albers et al., 1988a; Albers, 1988b). BPI undergoes two phase transitions: antiferrodistortive $\left(\mathrm{P} 2_{1} / \mathrm{m}(\mathrm{Z}=2) \rightarrow \mathrm{P}_{1} / \mathrm{c}(\mathrm{Z}=4)\right)$ at $\mathrm{T}_{\mathrm{c} 1}=355 \mathrm{~K}$ and ferroelectric phase transition $\left(\mathrm{P} 2_{1} / \mathrm{c}(\mathrm{Z}=4) \rightarrow \mathrm{P} 2_{1}(\mathrm{Z}=4)\right)$ at $\mathrm{T}_{\mathrm{c} 2} \approx 198-224 \mathrm{~K}$ (Albers et al., 1988a; Fehst et al., 1993). Unit cell parameters: $\mathrm{a}=11.191(3) \AA, \mathrm{b}=7.591(3) \AA, c=12.447(6) \AA ⿻, 1=116.62(2)^{\mathrm{o}}$ at RT. In BPI structure the inorganic tetrahedral $\mathrm{HPO}_{3}$ groups are linked by hydrogen bonds forming zig-zag chains along monoclinic $b$ - axis. The betaine molecules are arranged almost perpendicular to the chains along $\mathrm{x}$ directions and linked by one hydrogen bond to the inorganic group. The ordering of hydrogen ions in the hydrogen bonds in the chains results in ferroelectric phase transition. The spontaneous polarization below $\mathrm{T}_{\mathrm{c} 2}$ occurs along monoclinic $b-$ axis. The transition temperature $T_{c 2}$ appears to be sensitive to a small percentage of impurities or to crystalline defects. Deuteration of the hydrogen bonds can increase the ferroelectric phase transition temperature $T_{\mathrm{c} 2}$ up to $310 \mathrm{~K}$ (Bauch et al. 1995). 
Fig.1 show the temperature dependence of dielectric constant $\varepsilon_{\mathrm{b}}$ in BPI at ferroelectric phase transition. Maximal values of $\mathrm{P}_{\mathrm{s}} \approx 1.710^{-2} \mathrm{Cm}^{-2}$ in BPI are smaller than in TGS $\left(\mathrm{P}_{\mathrm{s}} \approx 4.510^{-2}\right.$ $\mathrm{Cm}^{-2}$ Albers et al., 1988).

The antiferrodistortive phase transition in BPI at $\mathrm{T}_{\mathrm{c} 1}$ is not accompanied by appearance of polarization. Nevertheless the temperature dependence of dielectric constant exhibit small anomaly at $\mathrm{T}=\mathrm{T}_{\mathrm{c} 1}$ that indicates a connection between order parameters of antiferrodistortive and ferroelectric phase transition.

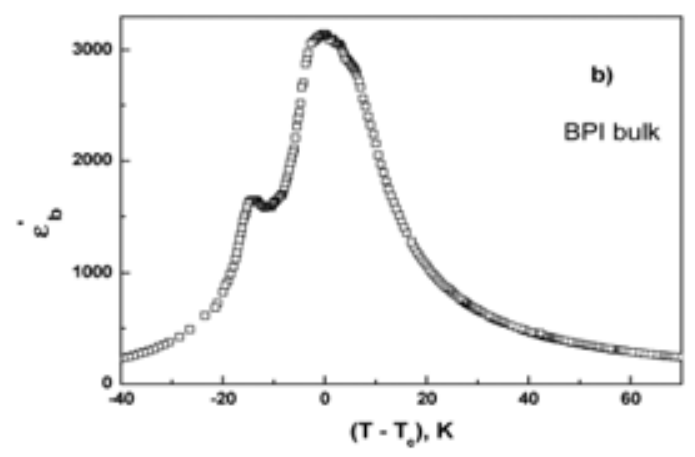

Fig. 1. Temperature dependence of dielectric constant along b axis in BPI (Balashova et al., 2002).

The dielectric and acoustic properties of BPI, and crystals of betaine phosphite with small admixture of antiferroelectric betaine phosphate, at the antiferrodistortive and ferroelectric phase transitions were explained using the thermodynamic approach based on Landau theory with account of $\xi \eta^{2} \mathrm{P}^{2}(\xi<0)$ term coupling the $\eta$ nonpolar order parameter for hightemperature antiferrodistortive phase transition at $\mathrm{T}_{\mathrm{c} 1}$ and polarization $\mathrm{P}$ (Balashova \& Lemanov, 2000, 2003b). The thermodynamic potential has a form:

$$
F=\frac{1}{2} \alpha_{1} \eta^{2}+\frac{1}{6} \gamma_{1} \eta^{6}+\frac{1}{2 \chi_{0}} P^{2}+\frac{1}{4} \beta_{2} P^{4}+\frac{1}{2} \xi \eta^{2} P^{2}-P E
$$

where $\alpha_{1}=\lambda_{1}\left(T-T_{c 1}\right), \beta_{1}=0$ (the tricritical point), $\beta_{2}>0, \gamma_{1}>0, \xi<0, \mathbf{E}$ is the macroscopic electric field; $\chi_{0}$, the background dielectric susceptibility. Only one coefficient $\alpha_{1}$ in this approach is temperature dependent. Since in the considered potential only one coefficient at $\eta^{2}$ term changes the sigh at $T_{c 1}$, the ferroelectric phase transition at $T_{c 2}$ was called trigger phase transitions (Holakovsky, 1973). The thermodynamic potential (1) can be rewritten in a dimensionless form (Balashova et al.,2002; Balashova \& Lemanov, 2003a)

$$
\mathrm{f}=\frac{1}{2} \mathrm{ta}^{2} \mathrm{q}^{2}+\frac{1}{6} \mathrm{q}^{6}-a \mathrm{p}^{2}+\frac{1}{2} \mathrm{p}^{4}-\mathrm{q}^{2} \mathrm{p}^{2}+2 \mathrm{ape}
$$

where $\mathrm{t}=\left(\mathrm{T}-\mathrm{T}_{\mathrm{c} 1}\right) / \Delta \mathrm{T}$ is the reduced temperature, $\mathrm{f}=\mathrm{F} \cdot \frac{8 \beta_{2}^{3} \gamma_{1}^{2}}{\xi^{6}}, \mathrm{q}^{2}=\frac{2 \beta_{2} \gamma_{1}}{\xi^{2}} \eta^{2}$, $\mathrm{p}^{2}=-\frac{2 \beta_{2}^{2} \gamma_{1}}{\xi^{3}} \mathrm{P}^{2}, \mathrm{e}=\frac{\sqrt{2 \gamma_{1}} \beta_{2} \chi_{0}}{(-\xi)^{3 / 2}} \mathrm{E}$ 
Parameter $\Delta \mathrm{T}=\frac{\gamma_{1}}{\lambda_{1} \chi_{0}^{2} \xi^{2}}$ determines the temperature region of stability of the paraelectric antiferrodistortive phase $(q \neq 0, p=0)$. The dimensionless parameter $a=\frac{2 \beta_{2} \gamma_{1}}{\chi_{0}} \xi^{3}<0$ defines the region of stability of the polar mixed phase $(q \neq 0, p \neq 0)$ and the order (first, second or tricritical) of the phase transition into polar mixed phase. An important conclusion of these works is that the ferroelectric phase transition into the $(\eta \neq 0, P \neq 0)$ state in BPI crystals is induced by the nonpolar order parameter $\eta$ due to the $\eta^{2} \mathrm{P}^{2}$ coupling and the temperature of the ferroelectric phase transition $\mathrm{T}_{\mathrm{c} 2}$ is determined by the coupling strength. This approach makes it possible adequately describe the nonlinear temperature dependences of the inverse dielectric constant in the antiferrodistortive phase of the $\mathrm{BPI}_{1-\mathrm{x}} \mathrm{BP}_{\mathrm{x}}(\mathrm{x}=0-0.1)$, including the phase transition region, the effect of the bias field on dielectric constant and the acoustic anomalies at the ferroelectric phase transition. In BPI the value of dimensionless parameter a is -2.5. Application of the model of coupled order parameters for betaine arsenat deuterated betaine arsenate system was presented in ref. (Balashova et al., 1995).

\section{Preparation of films}

\subsection{BPI films}

Thin films of betaine phosphite (BPI) were grown on different substrates by evaporation method from the water solution of the BPI crystals at a temperature of $24^{\circ} \mathrm{C}$. Singlecrystalline quartz $\alpha-\mathrm{SiO}_{2}$ (Z-cut), lithium niobate $\mathrm{LiNbO}_{3}$ (Y-cut) (Balashova et al., 2008; 2009a,b), $\mathrm{a}-\mathrm{Al}_{2} \mathrm{O}_{3}(110), \mathrm{NdGaO}_{3}(001)$, and also fused quartz (Balashova et al.,2011) and glass were used as substrates. Before the film growth $\mathrm{Al}$ or $\mathrm{Au}$ interdigital structures (IDS) of electrodes were deposited on the substrates by the photolithographic method. Fig.2 shows schematically an arrangement of the IDS and the BPI film on substrate. The length, width and thickness of IDS electrodes were $4 \mathrm{~mm} \times(25 \mu \mathrm{m}$ or $50 \mu \mathrm{m}) \times 0.3 \mu \mathrm{m}$. The distance between electrodes was equal to the width of electrodes $(25 \mu \mathrm{m}$ or $50 \mu \mathrm{m})$. The number $\mathrm{N}$ of pairs of electrodes in IDS was $\mathrm{N}=$ (35 or 40). Total aria of IDS was $35 \mathrm{~mm}^{2}$. The thickness $\mathrm{h}$ of films measured by profilometer was $\mathrm{h}=(0.5-4) \mu \mathrm{m}$.

The aqueous solution of BPI crystals was deposited both in the IDS region and directly on the substrate surface. Thin layer of solution is practically invisible just after the rendering on the substrate but in some minutes the crystallization front moving from the border to the center of the substrate is observable when the substrate is oriented horizontally. If one of the borders of the substrate is higher than opposite, the crystallization front moves from the upper to the lower border. This shows that the crystallization process starts from the areas with the smallest thickness of solution layer.

The measurements of IDS resistance and dielectric response show that the crystallization process may be characterized by two stages. At the first stage, which takes several minutes, after the stop of the crystallization front, the resistance is about $R \approx(2-6) \mathrm{MOhm}$. Dielectric response shows considerable frequency dispersion of capacity and losses at $\mathrm{T}>240 \mathrm{~K}$. At this stage the block structure nevertheless is well observable in polarization microscope. In the second stage which takes several days the IDS resistance becomes higher than 20 MOhm. After this, the films exhibit low frequency dispersion of capacity and low value of dielectric losses at room temperature. Existence of two stages of crystallization is due to the fact that the BPI crystallization begins from the surface which is in direct contact with air. 
Water evaporates from the surface, and the crystallization front gradually propagates down to the substrate. However, the crystallized part of the film hinders the evaporation from the layers near the film-substrate interface. For this reason the interface may contain noncrystallized regions for a fairly long time, which eventually crystallize. These regions have certain conductivity, which is responsible for the low frequency dispersion of the capacitance and losses during second stage of crystallization.

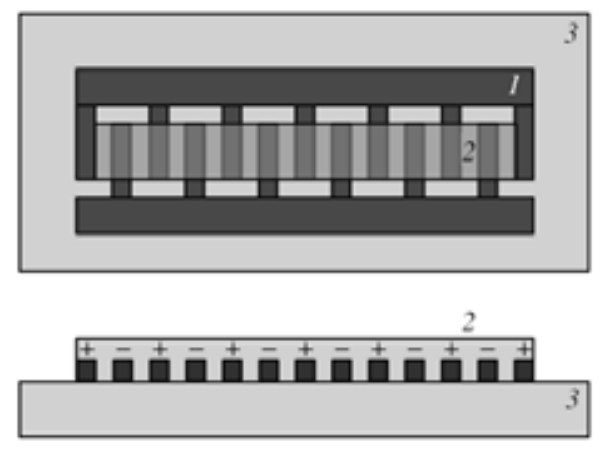

Fig. 2. Arrangement of (1) the IDS and (2) the BPI film on (3) substrates. The plus and minus signs identify the alternating charge distribution on the IDS electrodes when DC electric voltage is applied to IDS.

\subsection{DBPI films}

DBPI films with different degrees of deuteration were fabricated by evaporation from solutions of (i) BPI single crystals in heavy water $\mathrm{D}_{2} \mathrm{O}$, and (ii) DBPI single crystals, obtained by the recrystallization of BPI crystals in $\mathrm{D}_{2} \mathrm{O}$, and (iii) DBPI single crystals, grown by slow cooling from a solution of $\mathrm{D}_{3} \mathrm{PO}_{3}$ acid and betaine, in heavy water. The degree of deuteration was determined from the ferroelectric phase transition temperature, which, according to the data on DBPI single crystals, increases with an increase in the degree of deuteration (Bauch et al., 1995). $\mathrm{NdGaO}_{3}(001)$, sapphire, and quartz a-SiO${ }_{2}(001)$ single crystals were used as substrates onto which interdigital gold structures were previously deposited by photolithography.

\subsection{TGS films}

In ref. (Wurfel \& Barta, 1973; Wurfel et al., 1973) a polycrystalline ferroelectric TGS films with switching characteristics approaching those of a bulk crystal were prepared by sublimation in vacuum onto silicon substrates. Nevertheless, preparation of oriented (textured) films adaptable to present day planar technologies remains a topical problem. A study of the growth of TGS crystals from a saturated solution on single crystal silicon substrates and of the effect of various substrate surface treatments on the size and orientation, as well as the structure of crystallites, was reported in (Stekhanova et al., 2005). In this work TGS films were grown on substrates of fused quartz atop a layer of thermally deposited aluminum $\left(\mathrm{Al} / \mathrm{SiO}_{2}\right)$, as well as on white sapphire $\left(\mathrm{a}-\mathrm{Al}_{2} \mathrm{O}_{3}\right)$ substrates with IDS of electrodes. The TGS films were prepared by evaporation of a saturated water solution of bulk crystals which was deposited on the substrate at room temperature. The thickness of TGS films was $h \approx 0.2 \mu \mathrm{m}$. 


\section{Block and crystal structure of films}

\subsection{BPI films}

Block structure of films can be visualized by means of polarizing microscope in reflection mode because BPI as well as other amino acid ferroelectrics belongs to low symmetry class and are characterized by strong birefringence that provides the possibility to observe different single crystalline areas in the film. Figure 3 presents images of a BPI film deposited on the Z-cut quartz surface in the IDS region, which were obtained in polarized light in reflection mode. The $Z$-cut quartz plate is not birefringent, and does not influence the contrast when rotated about an axis perpendicular to the surface, with the polarizers in the extinction position. The film deposited on the quartz surface induces birefringence. We readily see (Fig. 3) that when the crystal with the film is turned around the position of crossed polarizers (or when the crossed polarizers are turned relative to the crystal with the film), different areas of the film with different orientations of optical indicatrix main directions in the film plane become extinct. In each of these areas, extinction occurs after a turn through $90^{\circ}$. Thus, one may conclude that the BPI film is essentially a polycrystal with block dimensions much larger than the film thickness. The blocks dimensions may reach $\sim 1 \mathrm{~mm}$, which can be easily derived from Fig. 3 by comparing the blocks with the dimensions of the IDS electrodes and their separation, with the sum being $50 \mu \mathrm{m}$. Similar results were obtained for BPI films on lithium niobate $\mathrm{LiNbO}_{3}$ and $\mathrm{NdGaO}_{3}$ as well (Fig.4 and Fig.5).

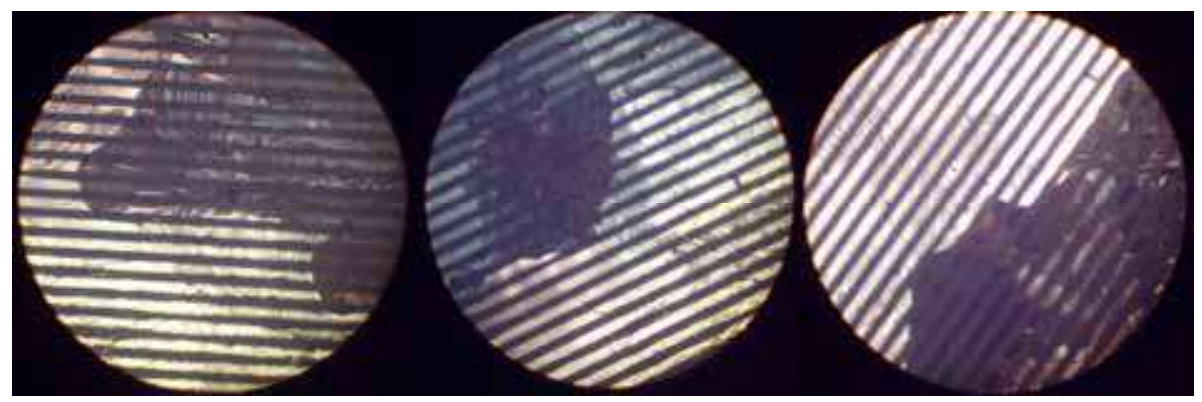

Fig. 3. Images of the BPI film grown on $\mathrm{SiO}_{2}$ (Z-cut) substrate obtained with a polarizing microscope operating in reflection for different orientations of the films relative to crossed polarizers (the IDS electrode separation is $25 \mu \mathrm{m}$ ). Diameter of image is $\mathrm{d}=1 \mathrm{~mm}$.

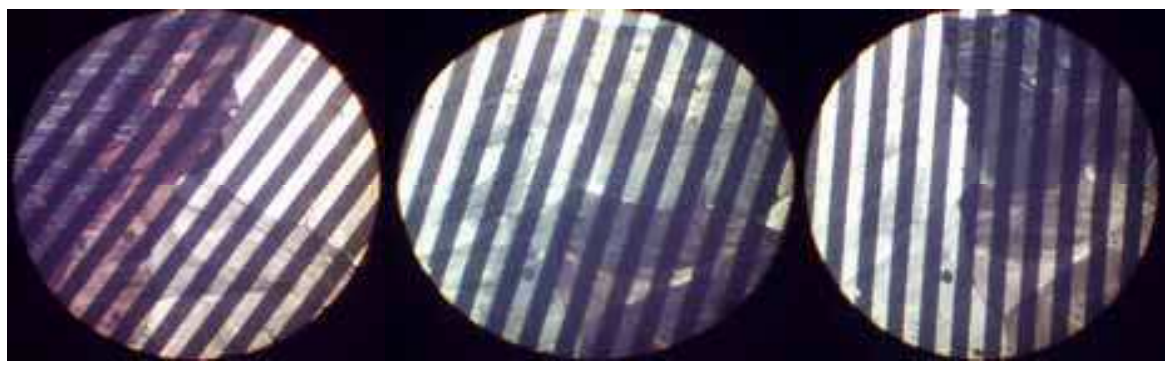

Fig. 4. Images of the BPI film grown on the $\mathrm{LiNbO}_{3}$ substrate at different orientations of the films relative to crossed polarizers. The IDS electrode separation is $50 \mu \mathrm{m}$. 


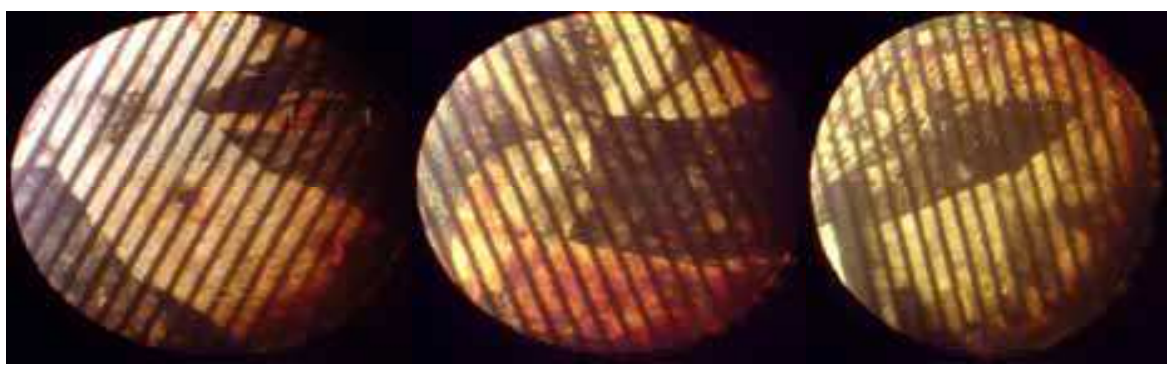

Fig. 5. Images of the BPI film grown on the $\mathrm{NdGaO}_{3}(001)$ substrate at different orientations of the films relative to crossed polarizers.

\subsection{DBPI films}

The structure of single crystal blocks formed on the substrate surface during crystallization of DBPI is analogous to BPI films. Usually the number of blocks in the aria of the IDS structure usually does not exceed 5-10. Sometimes we managed to obtain the DBPI films with only two and even one single crystalline block per aria of the IDS. Fig. 6 demonstrates typical images of the DBPI film block structure in film with two blocks.

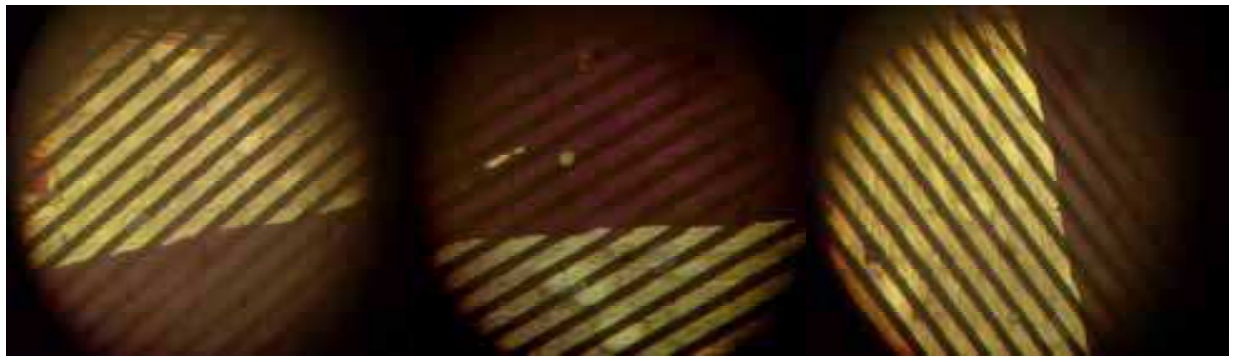

Fig. 6. Images of the DBPI film grown on the $\mathrm{NdGaO}_{3}(001)$ substrate at different orientations of the films relative to crossed polarizers.

\subsection{TGS films}

Figure 7 and 8 presents images of TGS films grown on $\mathrm{Al} / \mathrm{SiO}_{2}$ and $\mathrm{a}-\mathrm{Al}_{2} \mathrm{O}_{3}$ substrates obtained with a polarization microscope in reflection. The microscope field of view was 1 $\mathrm{mm}$. Rotation of the films about crossed polarizers showed that the films are polycrystalline and consist of blocks measuring $0.1-0.3 \mathrm{~mm}$ for films on $\mathrm{Al} / \mathrm{SiO}_{2}$, and elongated blocks, 0.1 $\times 1 \mathrm{~mm}$ in size, on $\mathrm{a}-\mathrm{Al}_{2} \mathrm{O}_{3}$. In blocks extinction was observed to occur each $90^{\circ}$ of rotation of the film with respect to the crossed polarizers, thus evidencing the blocks to be single crystals.

\subsection{X-Ray analysis}

The orientation of crystallographic axes in blocks was determined by X-ray diffraction on a Dron 3 diffractometer $\left(\mathrm{Cu} K_{\alpha}\right.$ radiation). Figure 9 shows a $\theta-2 \theta$ diffraction pattern for a DBPI film composed of two blocks (see Fig. 11). The presence of strong narrow lines in the diffraction patterns, which correspond to (200), (300), (400), (500), and (600) reflections, is indicative of a pronounced DBPI crystal structure, almost without foreign phases. The 


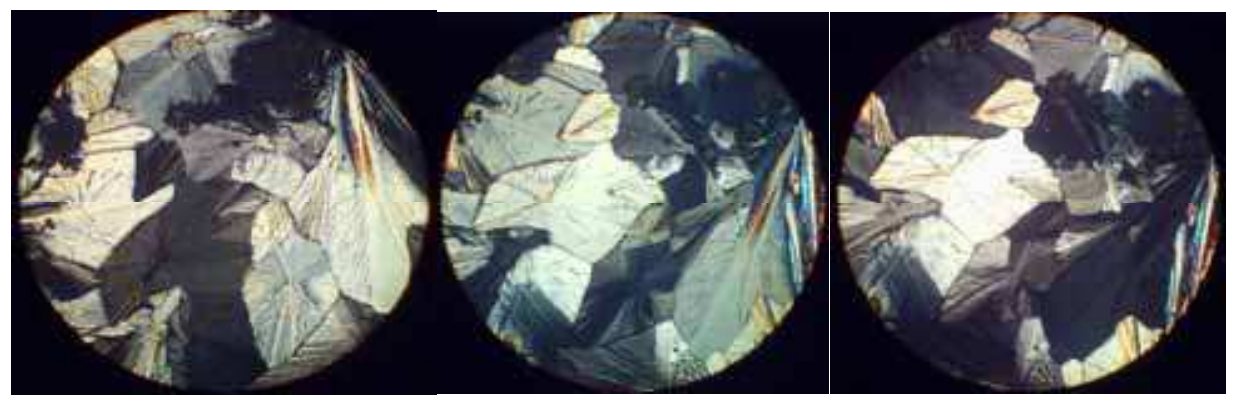

Fig. 7. Images of the TGS film grown on the $\mathrm{Al} / \mathrm{SiO}_{2}$ substrate at different orientations of the films relative to crossed polarizers.
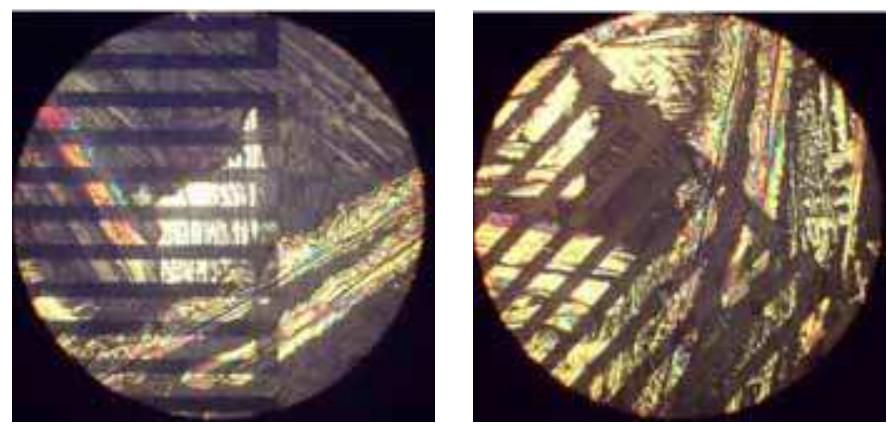

Fig. 8. Images of the TGS film grown on sapphire substrates with interdigital electrode structures at different orientations of the films relative to crossed polarizers.

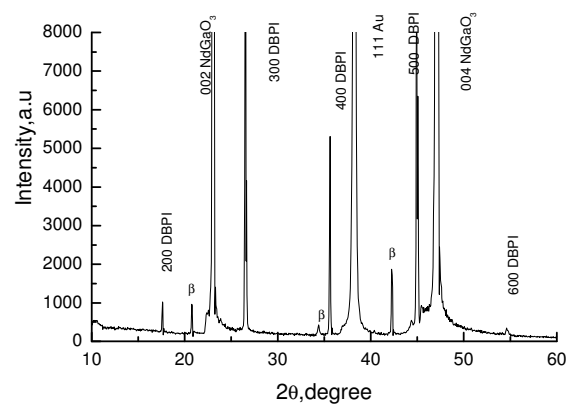

Fig. 9. $\theta-2 \theta$ diffraction patterns of the $\mathrm{DBPI} / \mathrm{NdGaO}_{3}$ structure, which is composed of two single crystal blocks (Fig. 6), with the identification of the peaks from the substrate, film, and gold interdigital electrodes. The bands denoted as $\beta$ are due to the spurious $\mathrm{CuK} K_{\beta}$ radiation.

absence of other reflections shows that the polar axis (monoclinic b axis) in both blocks is oriented in the substrate plane, and blocks differ by the orientation of $b$ and $c$ axes in the film plane. The (100) plane is parallel to the substrate surface in both blocks (correspondingly, the $a^{*}$ axis is oriented perpendicularly to the film plane). 


\section{Small signal dielectric response in BPI films}

The capacity and dielectric losses of the films were measured by a LCR meters MIT9216A at frequencies of $\mathrm{f}=0.12,1,10,100 \mathrm{kHz}$ and by a E7-12 at $\mathrm{f}=1 \mathrm{MHz}$ with a drive voltage $\mathrm{U}_{\sim}=$ $0.1 \mathrm{~V}$ in the temperature region $\mathrm{T}=(120-340) \mathrm{K}$. In the case of substrates with IDS the measured capacity of film/IDS/substrate structure is related basically to the in-plane orientation of electric field. The change of IDS/substrate capacity $\mathrm{C}_{\text {sub }}$ after the film growth reflects therefore the in-plane dielectric properties of the film.

\subsection{Non-centrosymmetric substrates $\alpha-\mathrm{SiO}_{2}, \mathrm{LiNbO}_{3}$}

Figure 10 plots temperature dependences of the capacitance of the $\mathrm{BPI} / \alpha-\mathrm{SiO}_{2}$ structure measured across the IDS electrodes at frequencies of $120 \mathrm{~Hz}, 1,10$, and $100 \mathrm{kHz}$. At room temperature, the IDS capacitance is increased by the presence of the BPI film by $13.7 \mathrm{pF}$ to become $23 \mathrm{pF}$. As the temperature is lowered, the capacitance of the structure grows markedly and reaches a maximum at $\mathrm{T} \approx 225 \mathrm{~K}$, the temperature of the ferroelectric phase transition in a bulk crystal, after which it decreases with further lowering of temperature. There is practically no frequency dispersion, and the maxima in capacitance seen at different frequencies do not shift with temperature (Fig. 10). The variations of the permittivity of quartz in this temperature interval being small, all temperature-induced changes in the capacitance of the structure should be assigned to variation of the permittivity in the BPI film. Thus, the permittivity of the film at the maximum increases more than tenfold compared with the value at room temperature. Dielectric losses in the $\mathrm{BPI} / \mathrm{SiO}_{2}$ structure practically do not vary below room temperature and are less than 0.02 in the $(0.12-100) \mathrm{kHz}$ frequency range.

Figures 11 and 12 present temperature dependences of the capacitance of the BPI/SiO and $\mathrm{BPI} / \mathrm{LiNbO}_{3}$ structures which were obtained without and with a bias field $\mathrm{U}=0,9$ and $18 \mathrm{~V}$ applied to the IDS. The maxima of capacitance in both structures in the absence of bias are seen to practically coincide in their temperature position $(\mathrm{T} \approx$ $225 \mathrm{~K})$.

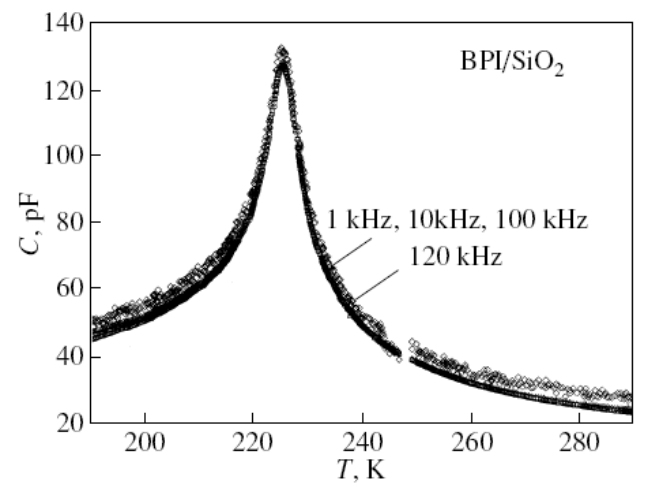

Fig. 10. Temperature dependences of the capacitance of the $\mathrm{BPI} / \mathrm{SiO}_{2}$ structure at frequencies of $120 \mathrm{~Hz}$ and 1, 10, and $100 \mathrm{kHz}$ (Balashova et al., 2009a).

Application of a bias reduces the maximum capacitance, diffuses the maximum in temperature and shifts it toward higher temperatures, as is the case with bulk BPI crystals. 
At room temperature, the capacitance of IDS on $\mathrm{LiNbO}_{3}$ grows due to the film by about 3.8 $\mathrm{pF}$. The film-induced capacitance at the maximum at $225 \mathrm{~K}$ increases almost by an order of magnitude, just as in the $\mathrm{BPI} / \alpha-\mathrm{SiO}_{2}$ structure.

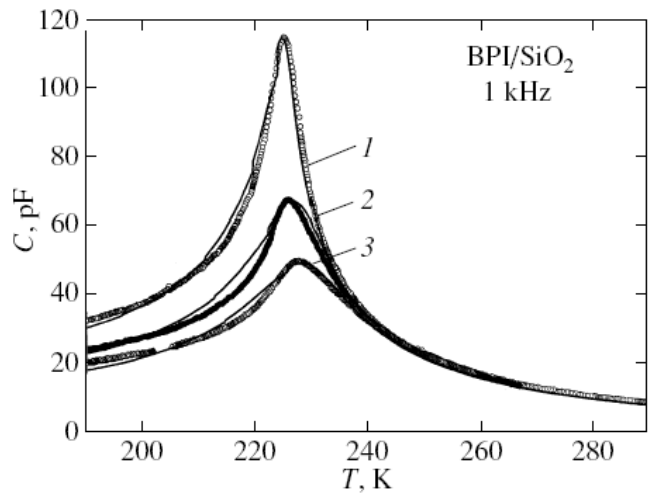

Fig. 11. Temperature dependences of the film capacitance in the $\mathrm{BPI} / \mathrm{SiO}_{2}$ structure measured without and with application of a bias field $\mathrm{U}_{=}=$ (1) 0, (2) 9, and (3) $18 \mathrm{~V}$. Solid lines plot the results of the calculation $(\mathrm{a}=-2.5$ (Balashova et al., 2009a).

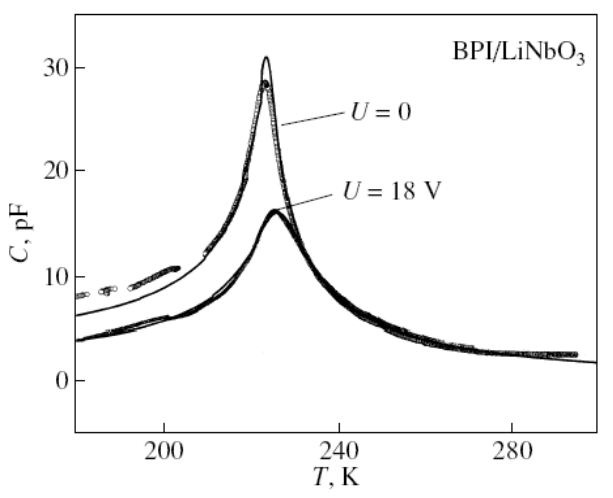

Fig. 12. Temperature dependences of the film capacitance in the $\mathrm{BPI} / \mathrm{LiNbO}_{3}$ structure measured without and with application of a bias field $\mathrm{U}_{=}=0$ and $18 \mathrm{~V}$ to IDT. Solid lines plot the results of the calculation ( $\mathrm{a}=-2.5$ (Balashova et al., 2009a).

Figure 13 illustrates the behavior with temperature of the capacitance $\mathrm{C}$ and $\tan \delta$ of the $\mathrm{BPI} / \mathrm{LiNbO}_{3}$ structure measured at frequencies of $1,10,100 \mathrm{kHz}$ and $1 \mathrm{MHz}$. As in the case of the $\alpha-\mathrm{SiO}_{2}$ substrate, at the maximum the capacitance exhibits practically zero dispersion in frequency. The temperature at which the capacitance reaches maximum does not depend on frequency. As the temperature is increased above the room temperature, the permittivity reveals dispersion. The value of $\tan \delta$ is very small in the region of the maximum capacitance and falls off with decreasing temperature at all frequencies, without exceeding 0.01 . However, $\tan \delta$ grows strongly above room temperature. As seen from Fig. 13, the temperature dependences of the capacitance and of tan $\delta$ measured at $100 \mathrm{kHz}$ drops out of the general pattern of relations measured at four frequencies. In the (240-270) K interval, the capacitance at $100 \mathrm{kHz}$ is larger than that at $1,10 \mathrm{kHz}$ and $1 \mathrm{MHz}$, while above $270 \mathrm{~K}$ it is smaller than at the other frequencies. In contrast to the other frequencies, at $100 \mathrm{kHz}$ one observes a maximum of tan $\delta$ at approximately $270 \mathrm{~K}$ (Fig. 13b). Significantly, the roomtemperature capacitance of IDS on lithium niobate without film, measured also at $100 \mathrm{kHz}$, was smaller than that at $0.12,1,10 \mathrm{kHz}$ and $1 \mathrm{MHz}$. Thus, the unusual temperature dependences of the capacitance and tan $\delta$ of the $\mathrm{BPI} / \mathrm{LiNbO}_{3}$ structure at $100 \mathrm{kHz}$ should be assigned not to the BPI film but rather to the properties of the substrate, the crystalline piezoelectric lithium niobate.

The anomalous behavior of the capacitance $C$ and tand at temperatures above the temperature of the maximum in capacitance (Fig. 13a), which is observed in the BPI/ $\mathrm{LiNbO}_{3}$ structure at $100 \mathrm{kHz}$, suggests that at $100 \mathrm{kHz}$ the structure falls into a region of resonance extending in temperature by about $100 \mathrm{~K}$. For T $>270 \mathrm{~K}$, the frequency turns out to be above the resonance, and for $\mathrm{T}<270 \mathrm{~K}$, below the resonance frequency. The low resonance 
frequency $(\sim 100 \mathrm{kHz})$ is typical of the bulk electromechanical resonance of the substrate, which is not connected in any way with the film properties. Indeed, at $100 \mathrm{kHz}$ the wavelength of the shear acoustic mode in lithium niobate is approximately $3.6 \mathrm{~cm}$, so that one half of the wavelength may be comparable with the substrate dimensions. The variation of the resonance frequency with temperature should be assigned to the acoustic wave velocity in lithium niobate increasing with decreasing temperature.
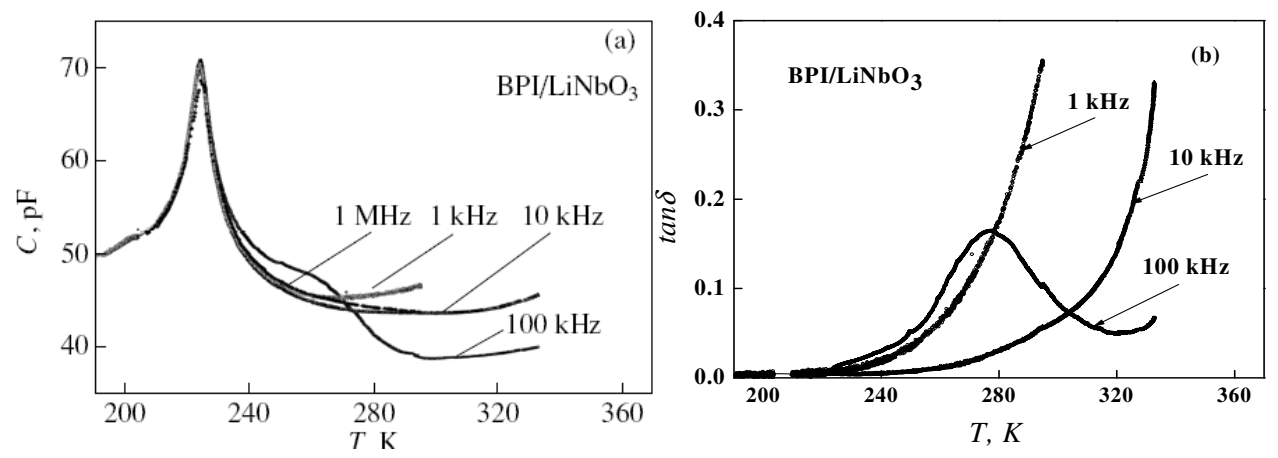

Fig. 13. Temperature dependences of (a) the capacitance and (b) tan $\delta$ of the $\mathrm{BPI} / \mathrm{LiNbO}_{3}$ structure at frequencies of 1, 10, and $100 \mathrm{kHz}$ and $1 \mathrm{MHz}$ (Balashova et al., 2009a).
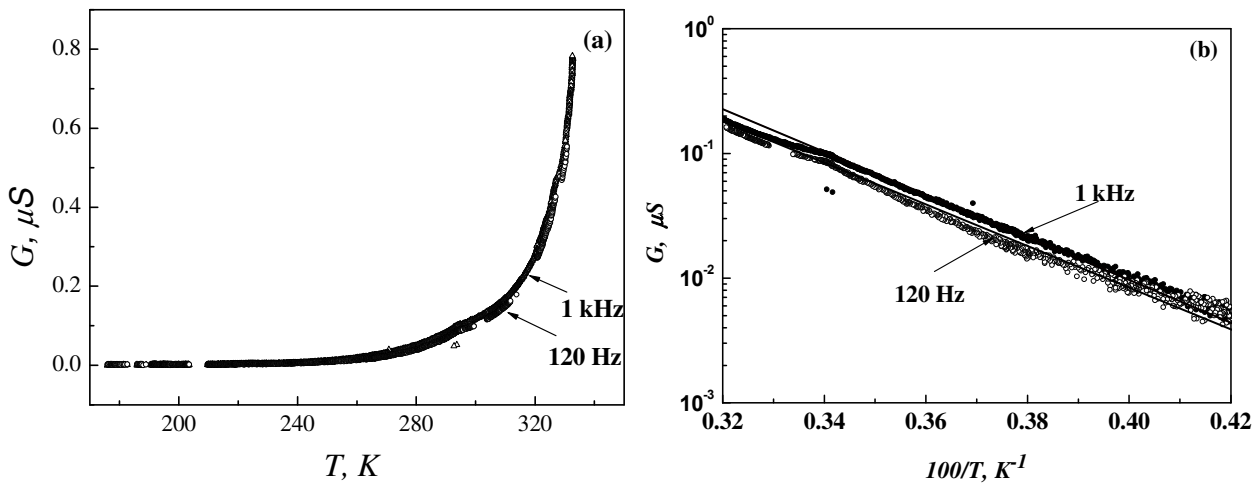

Fig. 14. (a) Temperature dependences of the conductivity $\mathrm{G}=\mathrm{C} \omega \tan \delta$ of the $\mathrm{BPI} / \mathrm{LiNbO}_{3}$ structure at frequencies of $120 \mathrm{~Hz}$ and $1 \mathrm{kHz}$ on a linear scale. (b) Dependences of $\mathrm{G}$ on the inverse temperature on a semilogarithmic scale (Balashova et al., 2009a).

As the temperature is raised, tano grows strongly in the (294-340) K range to reach $\sim 1$ (Fig.13b). This increase at the frequencies of $(0.12-1) \mathrm{kHz}$ is inversely proportional to frequency. Figure 14 plots temperature dependences of the conductivity $(G=C \omega \tan \delta)$ derived from the behavior with temperature of $\mathrm{C}$ and tan $\delta$ at the frequencies of $120 \mathrm{~Hz}$ and $1 \mathrm{kHz}$ for the BPI/LiNbO 3 structure. Examining Fig. 14, we see that the $\mathrm{G}(T)$ curves practically coincide at these frequencies. This suggests that the major contribution to these dependences is due to dc conductivity. In Fig. $14 \mathrm{~b}$, the $\mathrm{G}$ vs. $\mathrm{T}^{-1}$ relations are replotted in the log-linear coordinates. The graphs thus obtained can be fitted well with an exponential with 
an activation energy of about $10^{3} \mathrm{~K}(\sim 0.1 \mathrm{eV})$, a figure characteristic of thermally activated diffusion in films. Most probably, the conductivity here is mediated by diffusion of hydrogen atoms.

In bulk BPI crystals, a strong maximum in permittivity is observed only along the twofold axis $(\mathrm{Y})$, along which spontaneous polarization appears at the ferroelectric phase transition. Perpendicular to the polar axis, permittivity does not reveal noticeable anomalies and is rather small. The maximum capacitance observed in $\mathrm{BPI} / \mathrm{SiO}_{2}$ and $\mathrm{BPI} / \mathrm{LiNbO}_{3}$ structures at $\mathrm{T} \approx 225 \mathrm{~K}$ originates obviously from variation of permittivity in films, because the permittivity of substrates does not feature any noticeable changes in the temperature interval studied, and the temperature of the maximum coincides with that of the ferroelectric phase transition in bulk BPI crystals. In both structures, the permittivity of the film at its maximum exceeds by about an order of magnitude that at room temperature. As in single crystals, the maximum of capacitance does not shift in temperature with the frequency varied within a broad range, from $120 \mathrm{~Hz}$ to $1 \mathrm{MHz}$. Application of bias reduces the maxima in magnitude, diffuses them and shifts toward higher temperatures, just as the maxima in permittivity at the ferroelectric phase transition in a bulk BPI crystal.

Unlike a bulk BPI crystal, the phase transition in a film (Fig. 13b) is not accompanied by a pronounced increase of the loss tangent associated with domain wall motion. The absence of a domain contribution to dielectric losses should be apparently attributed to the fact that either domains in polycrystalline BPI films are pinned to defects near the interface with the substrate or the blocks with polarization oriented with the field in the film plane are singledomain because of a small depolarizing factor.

Thus, the temperature, field and frequency dependences of the capacitance of films are similar to those of bulk BPI crystals. At the same time, one could point out a few differences in the ferroelectric phase: (1) in zero bias, the capacitance of films decreases with temperature slower than it does in a bulk crystal; (2) in films one does not observe a domain contribution to dielectric losses; (3) in films, bias suppresses strongly the capacitance not only in the neighborhood of $T_{c}$ but at lower temperatures as well; and (4) the maximum in the temperature dependence of permittivity in films is more narrow than that in a bulk crystal.

\subsubsection{Dielectric permittivity of films}

The permittivity of films can be calculated using the relations derived (Kino \& Wagers, 1973) for the capacitance of an IDS located at the interface between the substrate and the film. In the case of a thin film, for $\gamma_{0} \mathrm{l} h<1$ and the separation between the IDS electrodes equal to the electrode width, the expression for the capacitance of one pair of IDS electrodes reduces to a simple form

$$
\mathrm{C}_{0}=\left(\frac{\pi^{3} \mathrm{w} \varepsilon_{0}}{32}\right)\left\{1+\varepsilon_{\mathrm{p}}^{\mathrm{II}}+\varepsilon_{\mathrm{p}}^{\mathrm{I}} \tanh \left(\gamma_{0}^{\mathrm{I}} \mathrm{h}\right)\right\}
$$

where $\mathrm{w}$ is the IDT electrode length, $\mathrm{h}$ is the film thickness, $\varepsilon_{0}$ is the permittivity of vacuum, $\varepsilon_{\mathrm{p}}=\left[\varepsilon_{\mathrm{xx}} \varepsilon_{\mathrm{zz}}-\varepsilon_{\mathrm{xz}}{ }^{2}\right]^{1 / 2}(\mathrm{x}$ is the direction in the substrate plane perpendicular to the IDS electrodes, $z$ is the direction perpendicular to the substrate plane), and $\gamma_{0} \mathrm{I}=\mathrm{k} \varepsilon_{\mathrm{p}} \varepsilon_{z z}(\mathrm{k}=2 \pi / \lambda$, where $\lambda$ is the spatial IDS field period). The upper indices I and II refer to the film and the substrate, respectively. At room temperature, the relative permittivity along and 
perpendicular to the polar axis in BPI crystals is $\varepsilon_{\mathrm{b}} \approx 160-200\left(\varepsilon_{x x}\right)$ and $\varepsilon_{\mathrm{a}} \approx \varepsilon_{\mathrm{c}} \approx 10\left(\varepsilon_{\mathrm{zz}}\right)$, respectively. For quartz, $\varepsilon_{\mathrm{xx}} \approx \varepsilon_{\mathrm{zz}} \approx 5$. The values of $\varepsilon_{\mathrm{p}}$ for the film and the substrate are $\approx$ 45 and $\approx 5$, accordingly, and $\gamma_{0} 1 \mathrm{~h} \approx 0.28$ for the film thickness $\mathrm{h}=1 \mu \mathrm{m}$ and $\lambda=100 \mu \mathrm{m}$. For these values of the parameters, $\gamma_{0}{ }^{1} \mathrm{~h}<<1$, and Eq. (3) can be recast to the form

$$
\mathrm{C}_{0}=\left(\frac{\pi^{3} \mathrm{w} \varepsilon_{0}}{32}\right)\left\{1+\varepsilon_{\mathrm{p}}^{\mathrm{II}}+\varepsilon_{\mathrm{xx}}^{\mathrm{I}} \mathrm{kh}\right)
$$

The total IDS capacitance ( $C_{\text {IDS }}$ ) is a product of $C_{0}$ by the number of IDS electrode pairs. Calculations performed using Eqs. (3) and (4) show that in the absence of a BPI film the capacitance of the IDS $\left(\mathrm{C}_{\mathrm{sub}}\right)$ on quartz and lithium niobate $(\mathrm{h}=0)$ is 9.3 and $40 \mathrm{pF}$, respectively, in full agreement with the measurements. As follows from calculations, the presence of a film $1 \mu \mathrm{m}$ thick with the relative permittivity $\varepsilon_{x x}=200$ and $\varepsilon_{z z}=10$ increases the IDS capacitance by $13.7 \mathrm{pF}$ on the quartz substrate, and by $4 \mathrm{pF}$ on lithium niobate, exactly what is observed experimentally (Table 1). Whence it follows that the permittivity of a BPI film on quartz at room temperature is close to that of a bulk BPI crystal along the monoclinic $b$ axis. This suggests that the $b$ axis in the single-crystal blocks of the film is oriented approximately perpendicular to the IDS electrodes.

\begin{tabular}{|c|c|c|c|c|}
\hline Substrate & $\mathrm{C}_{\text {sub }}$ calc. $(\mathrm{pF})$ & $\mathrm{C}_{\text {sub }}$ exp. $(\mathrm{pF})$ & $\mathrm{C}_{\text {IDS calc. }}(\mathrm{pF})$ & $\mathrm{C}_{\text {IDS }} \exp .(\mathrm{pF})$ \\
\hline$\alpha-\mathrm{SiO}_{2}$ & 9.3 & 9.3 & $23.5(\mathbf{b} \| \mathbf{k})$ & 23.0 \\
& & & $10.2(\mathbf{b} \perp \mathbf{k})$ & \\
\hline $\mathrm{LiNbO}_{3}$ & 39.8 & 39.9 & $43.7(\mathbf{b} \| \mathbf{k})$ & 43.8 \\
& & & $40.0(\mathbf{b} \perp \mathbf{k})$ & \\
\hline
\end{tabular}

Table 1. Calculated and experimental values of $\mathrm{C}_{\text {sub }}$ and $\mathrm{C}_{\text {IDS }}$ for the IDS/substrate and the BPI/IDS/substrate structures at $\mathrm{T}=294 \mathrm{~K}$.

Equation (4) is valid only for small values $\gamma_{0}{ }^{\mathrm{h}} \mathrm{h}<0.5$, where the nonlinearity of the $\tanh \left(\gamma_{0}{ }^{1} \mathrm{~h}\right)$ function is inessential. For large values of the argument, $\mathrm{C}$ is no longer linearly coupled with $\varepsilon_{x x}$. An increase in permittivity $\varepsilon_{x x}$ in the region of $\gamma_{0} 1 \mathrm{~h}>0.5$ will be accompanied by a slower growth of the IDS capacitance. Calculations show that for a film $1 \mu \mathrm{m}$ thick on $\mathrm{SiO}_{2}$ and $\lambda=$ $100 \mu \mathrm{m}$, the lack of proportionality between $\mathrm{C}$ and $\varepsilon_{x x}$ will produce a noticeable effect for $\varepsilon>$ 1500 (for $\varepsilon_{x x}=2000$, Eq. (3) yields a capacitance 15\% smaller than obtained from Eq. (4)). This should be borne in mind in describing temperature dependences of the permittivity of films, because in the region of the phase transition $\varepsilon_{x x}$ can exceed this value. Note, however, that the largest values of permittivity are observed only within a narrow temperature interval in the neighborhood of $\mathrm{T}_{\mathrm{c}}$. At temperatures already a few degrees above or below $\mathrm{T}_{\mathrm{c}}$, the permittivity of BPI decreases considerably, and the condition $\gamma_{0}{ }^{\mathrm{h}} \mathrm{h}<0.5$ is met. In the case of a BPI film on lithium niobate, with $\lambda=200 \mu \mathrm{m}$, the $\gamma_{0} \mathrm{~h} h<0.5$ condition is certain to be met, thus validating the use of Eq. (4) in an analysis of the behavior with temperature of the IDS capacitance.

\subsubsection{Thermodynamic description of dielectric anomaly}

As shown in (Balashova\&Lemanov,2000; Balashova et al.,2002), the ferroelectric phase transition at $\mathrm{T}=\mathrm{T}_{\mathrm{c} 2}=200-225 \mathrm{~K}$ in bulk BPI crystals is initiated by the order parameter $\eta$ of 
the high-temperature antiferrodistortive phase transition $\left(\mathrm{T}_{\mathrm{c} 1}=355 \mathrm{~K}\right)$, which is close to the tricritical point. To analyze the temperature dependences of the capacitance of the structures induced by the variation of permittivity in BPI films, we invoke the thermodynamic potential (1) used for describing the dielectric properties of bulk BPI crystals and include into it the elastic and striction energies:

$$
\mathrm{F}=\frac{1}{2} \alpha_{1} \eta^{2}+\frac{1}{6} \gamma_{1} \eta^{6}+\frac{1}{2 \chi_{0}} \mathrm{P}^{2}+\frac{1}{4} \beta_{2} \mathrm{P}^{4}+\frac{1}{2} \xi \eta^{2} \mathrm{P}^{2}-\frac{1}{2} \mathrm{~s}_{0} \sigma^{2}-\mathrm{QP}^{2} \sigma-\mathrm{PE}
$$

where $\alpha_{1}=\lambda_{1}(\mathrm{~T}-\mathrm{Tc} 1), \beta_{1}=0, \beta_{2}>0, \xi<0, \mathbf{E}$ is the macroscopic field, $\chi_{0}$ and $s_{0}$ are the background dielectric susceptibility and longitudinal elastic compliance, $\mathrm{P}$ is polarization, $\sigma$ is stress, and $Q$ is the electrostriction constant. The thermodynamic potential (3) can be reduced to a dimensionless form:

$$
\mathrm{f}=\frac{1}{2} \mathrm{ta}^{2} \mathrm{q}^{2}+\frac{1}{6} \mathrm{q}^{6}-\mathrm{ap} \mathrm{p}^{2}+\frac{1}{2} \mathrm{p}^{4}-\mathrm{q}^{2} \mathrm{p}^{2}-\frac{1}{2} \tilde{\omega}^{2}-\Delta \mathrm{s}^{1 / 2} \mathrm{p}^{2} \tilde{\omega}+2 \text { ape }
$$

where $t=(T-T c) / \Delta T$ is reduced temperature, $\Delta T=\gamma_{1} /\left(\lambda_{1} \chi_{0}^{2} \xi^{2}\right)$ defines the temperature interval of stability of the paraelectric antiferrodistortive phase $(\mathrm{q} \neq 0, \mathrm{p}=0)$ (in BPI crystals, $\Delta \mathrm{T}=\mathrm{T}_{\mathrm{c} 1}-\mathrm{T}_{\mathrm{c} 2}, \mathrm{f}=\mathrm{F} \cdot \frac{8 \beta_{2}^{3} \gamma_{1}^{2}}{\xi^{6}}, \mathrm{q}^{2}=\frac{2 \beta_{2} \gamma_{1}}{\xi^{2}} \eta^{2}, \mathrm{p}^{2}=-\frac{2 \beta_{2}^{2} \gamma_{1}}{\xi^{3}} \mathrm{P}^{2}, \mathrm{e}=\frac{\sqrt{2 \gamma_{1}} \beta_{2} \chi_{0}}{(-\xi)^{3 / 2}} \mathrm{E}, \varpi^{2}=\frac{8 s_{0} \beta_{2}^{3} \gamma_{1}^{2}}{\xi^{6}}$, and $\Delta \mathrm{s}=\frac{2 \mathrm{Q}^{2}}{\mathrm{~s}_{0} \beta_{2}}$ is the relative value of the jump in the elastic compliance at $\mathrm{T}_{\mathrm{c} 2}$. The dimensionless parameter $\mathrm{a}=\frac{2 \beta_{2} \gamma_{1}}{\chi_{0} \xi^{3}}<0$ defines the region of stability of the mixed polar phase $(q \neq 0, p \neq 0)$ and the order of the triggering ferroelectric phase transition. All information on the polarization response of the crystal and the closeness of the ferroelectric phase transition to the tricritical point is confined in the value of the dimensionless parameter a (in bulk BPI crystals, a = -2.5). Inclusion of the elastic and striction energies into the potentials (5) and (6) makes it possible to take into account the effect of substrate-induced film strains in the polarization response (Pertsev et al., 1988). Now the equations of state allowing for the film strains induced by the substrate take on the form

$$
\begin{aligned}
& \mathrm{u}_{\mathrm{s}}=\varpi+\Delta \mathrm{s}^{1 / 2} \mathrm{p}^{2} \\
& \mathrm{q}\left(\mathrm{ta}^{2}+\mathrm{q}^{4}-2 \mathrm{p}^{2}\right)=0 \\
& \mathrm{p}\left(-\mathrm{a}+\mathrm{p}^{2}-\mathrm{q}^{2}-\Delta \mathrm{s}^{1 / 2} \varpi\right)=- \text { ae }
\end{aligned}
$$

where $u_{s}$ is the longitudinal strain induced by the substrate in the film. The equations of state (7) lead one immediately to the following equation of state in the phase with $q \neq 0, p \neq$ 0 :

$$
-a p+(1-\Delta s) p^{3}-\Delta s^{1 / 2} u_{s} p-p \sqrt{2 p^{2}-t^{2}}=-a e
$$

The equation of state (8) yields a relation for susceptibility 


$$
\chi=\frac{\mathrm{x}_{\mathrm{o}}\left(-\mathrm{a}+\Delta \mathrm{s}^{1 / 2} \mathrm{p} \frac{\partial \mathrm{u}_{\mathrm{s}}}{\partial \mathrm{e}}\right) \cdot \sqrt{2 \mathrm{p}^{2}-\mathrm{ta}^{2}}}{\left[\left(-\mathrm{a}-\delta \mathrm{u}_{\mathrm{s}}+3(1+\Delta \mathrm{s}) \mathrm{p}^{2}\right) \cdot \sqrt{2 \mathrm{p}^{2}-\mathrm{ta}^{2}}-4 \mathrm{p}^{2}+\mathrm{ta}^{2}\right]}
$$

Because BPI films evaporated on different substrates have about the same temperature of the maximum of permittivity which is close to the ferroelectric transition point in bulk BPI crystals, one may neglect the effect of static strain exerted by the substrate on the film and set $\mathrm{u}_{\mathrm{s}} \approx 0$ in the absence of bias. With a bias applied to the IDS, the ensuing piezoelectric effect gives rise to generation in the piezoelectric substrate of periodic strains, which act on the film with the IDS period. These strains, constant in time but periodic in space, can bring about a spatially periodic variation of the phase transition temperature in the film, which would depend on the sign and magnitude of strains and manifest itself in a broadening of the maximum of permittivity. No noticeable broadening of the maximum is, however, observed; on the contrary, the permittivity peak is more narrow than that in a bulk crystal.

The polarization response can be affected, in addition to static strains, by dynamic strains of the piezoelectric substrate, which vary in space and time under the action of applied field. As evident from Eq. (9), the effect of dynamic strains on the permittivity of a film is defined by the relation $\Delta s^{1 / 2} p \partial u_{s} / \partial e$. This relation is actually the product of the piezoelectric coefficients in the film and the substrate expressed in relative units. Expressed in dimensional units, it assumes the form $Q P d_{s} / s_{0}$, where $d_{s}$ is the piezoelectric coefficient of the substrate, and QP/s $s_{0}=h_{f}$ is the piezoelectric coefficient of the film which derives from linearized electrostriction. Significantly, in the frame of this approach the film is free with respect to static strains but clamped relative to the dynamic ones. The strains in the film originate only from dynamic strains in the substrate. The contribution of dynamic strains should depend on the domain state of the film. Consider the effect of dynamic strains for two variants of the domain state of a BPI film in the ferroelectric phase: (1) the film is single-domain; (2) the film has a periodic domain structure in accordance with the period of the bias applied to the IDS. The ac electric field generated by the IDS in the film can be approximated as

$$
\mathrm{E}(\mathrm{x}, \mathrm{t})=\mathrm{E} \sim{ }^{0} \cos (\omega \mathrm{t}) \mathrm{M}(\mathrm{kx})
$$

where $\mathrm{M}(\mathrm{kx})$ is a meander-type function describing the spatial field distribution $(\mathrm{M}(\mathrm{kx})=0$ if the $\mathrm{x}$ coordinate is at the IDS electrodes, and $\mathrm{M}(\mathrm{kx})= \pm 1$ if $x$ is between the electrodes), $\mathrm{k}=$ $2 \pi / \lambda, \lambda$ is the IDS field period, and $E_{0}$ is the electric field amplitude. A dc bias $E_{\mathrm{dc}}$ applied to the IDS should have the same spatial distribution as E, i.e., it will be described by the $M(k x)$ function. Neglecting the scattering effects, one may assume that these fields in the film have only one component directed along the $x$ axis.

1. The single-domain state of a film is defined by uniform spontaneous polarization $P=P_{0}$ in the film plane. The ac electric field applied to the IDS electrodes creates in the substrate and, hence, in the film dynamic strains $u_{s d}=d_{s} E_{\sim}^{0} \cos (\omega t) M(k x)$, where $d_{s}$ is the piezoelectric coefficient of the substrate. The net variation of polarization in the film, mediated both by the electric field $E$ and by the external dynamic strains generated by the piezoelectric effect in the film, can be written as

$$
\Delta \mathrm{P}(\mathrm{t}, \mathrm{x})=\left(\chi+\mathrm{d}_{\mathrm{s}} \mathrm{e}_{\mathrm{f}}\right) \mathrm{E}_{\sim}{ }^{0} \cos (\omega \mathrm{t}) \mathrm{M}(\mathrm{kx})
$$

where $\chi$ is the susceptibility and $\mathrm{e}_{\mathrm{f}}=\chi_{0} \mathrm{~h}_{\mathrm{f}}$ is the piezoelectric coefficient of the film originating from linearization of the electrostriction. As follows from Eq. (11), both 
contributions to polarization variation are synchronized both in time and in space with the ac electric field (10). This means that the contribution to the IDS capacitance due to the time-varying polarization $\Delta \mathrm{P}(\mathrm{t})$, which is proportional to $\mathrm{M}(\mathrm{kx})$, is determined in this case by the parameter $\left(\chi+e_{f} d_{s}\right)$.

2. The polydomain state which is created by a dc field applied to the IDS is characterized by a periodically varying direction of polarization $\mathrm{P}=\mathrm{P}_{0} \mathrm{M}(\mathrm{kx})$. In this case, the contribution to polarization due to dynamic strains will alternate its sign in accordance with the variation of the direction of polarization. The total variation of polarization can be written as

$$
\begin{aligned}
\Delta \mathrm{P}(\mathrm{t}, \mathrm{x})= & \chi \mathrm{E}_{\sim}^{0} \cos (\omega \mathrm{t}) \mathrm{M}(\mathrm{kx})+\mathrm{e}_{\mathrm{f}} \mathrm{d}_{\mathrm{s}} \mathrm{E}_{\sim}^{0} \cos (\omega \mathrm{t}) \mathrm{M}(\mathrm{kx})^{2}= \\
& \left(\chi+\mathrm{e}_{\mathrm{f}} \mathrm{d}_{\mathrm{s}} \mathrm{M}(\mathrm{kx})\right) \mathrm{E}_{\sim}{ }^{0} \cos (\omega \mathrm{t}) \mathrm{M}(\mathrm{kx})
\end{aligned}
$$

As seen from Eq. (12), the contribution of dynamic strains to the variation of polarization is not synchronized in space with that of the electric field (10). The contribution of the film to the IDS capacitance will be determined by the magnitude of $\chi$, and the alternating contribution of dynamic strains will disappear when summation is performed over $x$. Thus, the contribution of the substrate-induced dynamic strains to the IDS capacitance associated with the film can be significant only if the ferroelectric film is in the single-domain state. Formation of a periodic domain structure precludes appearance of the dynamic strain effect completely.

Equation (9) for the susceptibility corresponds to the case of a single-domain ferroelectric film where the contribution due to dynamic strains is described by the term $\Delta \mathrm{s}^{1 / 2} \mathrm{p} \partial \mathrm{u}_{\mathrm{s}} / \partial \mathrm{e}$. In the case of a polydomain film with a period of the domain structure equal to that of IDS this term in Eq. (9) should be replaced with $\Delta s^{1 / 2} p(1-2 v) \partial u_{s} / \partial e$, with a proper allowance for domains with the negative $(v)$ and positive $(1-v)$ direction of polarization.

The maxima in permittivity observed experimentally in BPI films turned out more narrow than the ones calculated from Eq. (9). This cannot be attributed to the presence or absence of the dynamic strain contribution, because it is small in the vicinity of the phase transition, where the spontaneous polarization is small. The narrowing of the dielectric anomalies may be associated with the presence of the depolarizing electric field which reduces the external field e by an amount (e - np) proportional to $n$, i.e., the effective depolarizing factor expressed in relative units $\left(n=4 \pi N \chi_{0}\right)$. Now Eq. (9) for the susceptibility with allowance for dynamic strains and the depolarizing factor takes on the form

$$
\chi=\frac{\left.\chi_{0}\left(-\mathrm{a}+\Delta \mathrm{s}^{1 / 2}(1-2 v) \mathrm{p}\right) \frac{\partial \mathrm{u}_{\mathrm{s}}}{\partial \mathrm{e}}\right) \cdot \sqrt{2 \mathrm{p}^{2}-\mathrm{ta}^{2}}}{\left[\left(-\mathrm{a}(1+\mathrm{n})+3(1+\Delta \mathrm{s}) \mathrm{p}^{2}\right) \cdot \sqrt{2 \mathrm{p}^{2}-\mathrm{ta}^{2}}-4 \mathrm{p}^{2}+\mathrm{ta}^{2}\right]}
$$

where $\mathrm{p}(\mathrm{t})$ is calculated from the equation of state (8). In the absence of bias, the quantity $\chi(0)$ in the polar mixed phase $(q \neq 0, p \neq 0)$ can be extracted from Eq. (13) using the values of $\mathrm{p}(\mathrm{t})$ calculated from Eq. (8) at $\mathrm{e}=0$, and that in the paraelectric antiferrodistorsive phase $(\eta \neq 0, p=0)$, from Eq. (13) with $p(t)=0$. To obtain permittivity in the field $\chi(E)$ using Eq. (13), the values of $\mathrm{p}(\mathrm{t})$ are calculated numerically from the equation of state (8) for $\mathrm{e} \neq 0$. Figures 11 and 12 plot the temperature dependences of the capacitance in different bias fields calculated using Eq. (13) for the $\mathrm{BPI} / \mathrm{SiO}_{2}$ and $\mathrm{BPI} / \mathrm{LiNbO}_{3}$ structures, respectively. 


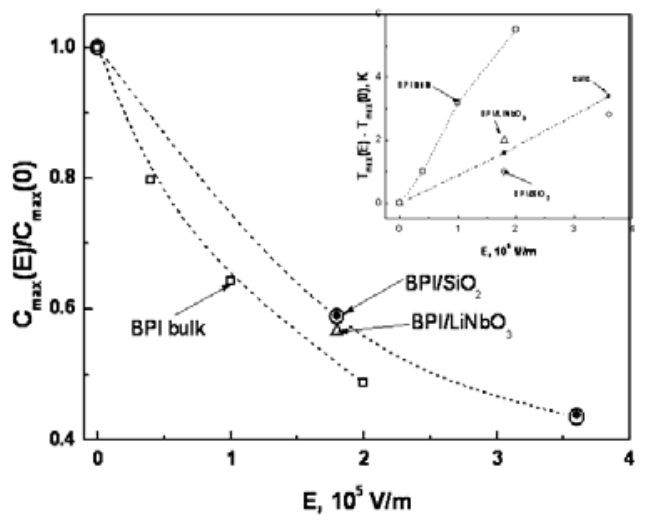

Fig. 15. Bias electric field dependences of the normalized capacity $C_{\max }(E) / C_{\max }(0)$ in the $\mathrm{BPI} / \alpha-\mathrm{SiO}_{2}$ structure and bulk BPI crystal. The insert shows the electric field dependence of $\mathrm{T}_{\max }(\mathrm{E})-\mathrm{T}_{\max }(0)$. Empty circles are calculations (Balashova et al.,2009b).

Figure 15 presents comparison of experimental and calculated bias electric field dependences of the normalized capacity $\mathrm{C}_{\max }(\mathrm{E}) / \mathrm{C}_{\max }(0)$ in the $\mathrm{BPI} / \alpha-\mathrm{SiO}_{2}, \mathrm{BPI} / \mathrm{LiNbO}_{3}$ structures and bulk BPI crystal, and the electric field dependence of $T_{\max }(E)-T_{\max }(0)\left(T_{\max }\right.$ is a temperature of maximal capacitance).

Good agreement between the experimental and calculated dependences (Figs. 11, 12, 15) was reached by allowing for (1) the extent to which the film was in the singledomain state, (2) dynamic strains, and (3) depolarizing field. In the absence of bias, it was assumed that the film was single-domain $(v=0)$ and, accordingly, the contribution due to dynamic strains was fully taken into account. With the bias applied, the best fit to experimental curves was reached for $v \neq 0$. The value of $v$ defining the volume of domains of opposite sign in the maximum field was $25 \%$. The contribution of dynamic strains was taken into account accordingly. The effective depolarizing factor in both structures turned out to be small, $N \approx$ 0.001. The low depolarizing field could possibly be assigned to the appearance of uncompensated pinned charges at the free boundary of the films.

\subsection{Centrosymmetric substrates: $\alpha-\mathrm{Al}_{2} \mathrm{O}_{3}, \mathrm{NdGaO}_{3}$}

The temperature dependences of the capacitance and in an as grown BPI film (after first stage of crystallization) on sapphire $a-\mathrm{Al}_{2} \mathrm{O}_{3}$ are shown in Figs. 16a and 16b. The same dependences, but measured a month after film preparation (after second stage of crystallization), are presented in Figs. 16c and 16d. One can see that there is almost no change in the $T_{c}$ temperature over time, and only the height of the capacitance peak at $T=$ $\mathrm{T}_{c}$ slightly decreases. The frequency dispersion of the capacitance and losses in the temperature range $\mathrm{T}>260 \mathrm{~K}$ completely disappears a month after film preparation. In contrast, the dispersion of the dielectric response remains below $\mathrm{T}_{\mathrm{c}}$, which indicates that the motion of the domain walls contributes to the dielectric relaxation. This fact suggests that the $\mathrm{BPI} / \mathrm{a}-\mathrm{Al}_{2} \mathrm{O}_{3}$ films have a domain structure below $\mathrm{T}_{\mathrm{c}}$, and domain walls are more weakly bound with defects at the interface between the centrosymmetric substrate and film than in the case of substrates with piezoelectric properties (BPI/ $\mathrm{LiNbO}_{3}$ and $\mathrm{BPI} / \mathrm{a}-$ $\left.\mathrm{SiO}_{2}\right)$. 

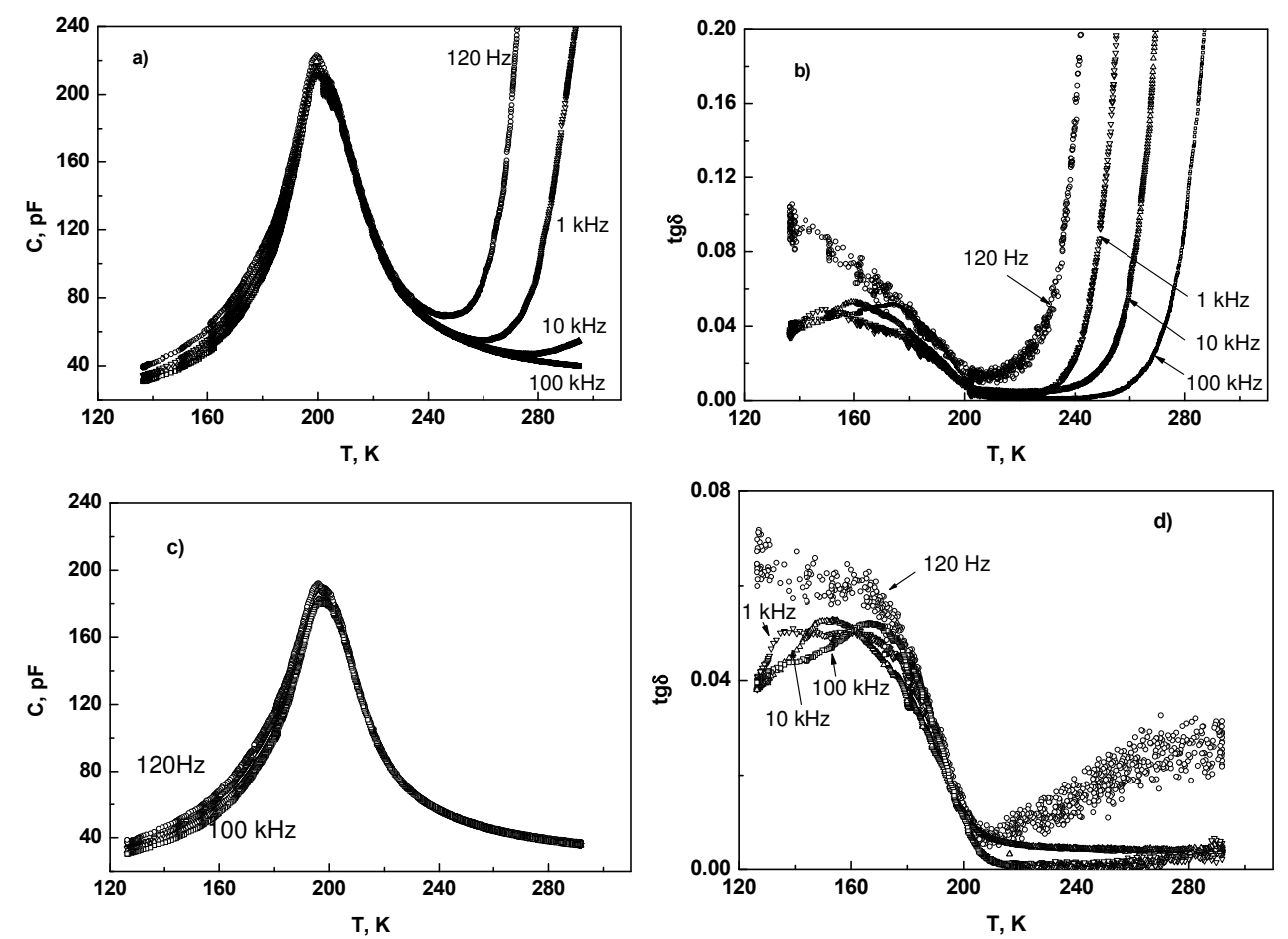

Fig. 16. Temperature dependences of the capacitance and $\operatorname{tg} \delta$ for the $\mathrm{BPI} / \mathrm{\alpha}-\mathrm{Al}_{2} \mathrm{O}_{3}$ structure, measured $(a, b)$ immediately after preparation and $(c, d)$ a month later (Balashova et al., 2011a).

Another difference in the properties of films grown on centrosymmetric and noncentrosymmetric substrates is the contribution that the interaction between the substrate and film makes to the structure capacitance. This interaction is due to the dynamic deformations, caused in a piezoelectric substrate by the electric field applied to the interdigital electrodes (reverse piezoelectric effect), which deform the film and lead to an additional contribution to the structure capacitance at $T<T_{c}$ (because of the direct piezoelectric effect). This interaction leads to a slower decrease in capacitance with a decrease in temperature below $\mathrm{T}_{\mathrm{c}}$ than in the bulk crystal. Obviously, this effect should not occur in the case of centrosymmetric substrates, where dynamic deformations are absent. The dependences that the normalized capacitance $C_{n}$ has on the difference $T-T_{c}$ for the $\mathrm{BPI} / \mathrm{a}-\mathrm{SiO}_{2}, \mathrm{BPI} / \mathrm{LiNbO}_{3}$, and $\mathrm{BPI} / \mathrm{a}_{-} \mathrm{Al}_{2} \mathrm{O}_{3}$ structures are compared in Fig. 17. The capacitance was normalized to make the dependence $C_{n}\left(T-T_{c}\right)$ for all structures coincide in the paraelectric phase. It can be seen that, for a structure with a centrosymmetric substrate (BPI/ $\mathrm{a}-\mathrm{Al}_{2} \mathrm{O}_{3}$ ), the capacitance decreases much more rapidly with a decrease in temperature below $\mathrm{T}_{\mathrm{c}}$. Even at $\mathrm{T}-\mathrm{T}_{\mathrm{c}}=-40 \mathrm{~K}$, the capacitance of this structure almost coincides with the background, to which it tends at high temperatures $\left(\left(\mathrm{T}-\mathrm{T}_{\mathrm{c}}\right) \approx 60 \mathrm{~K}\right)$. In contrast, for the $\mathrm{BPI} / \mathrm{a}-\mathrm{SiO}_{2}$ and $\mathrm{BPI} / \mathrm{LiNbO}_{3}$ structures, the capacitance at $\mathrm{T}-\mathrm{T}_{\mathrm{c}}=-40 \mathrm{~K}$ exceeds the background value by a factor of 2 . 


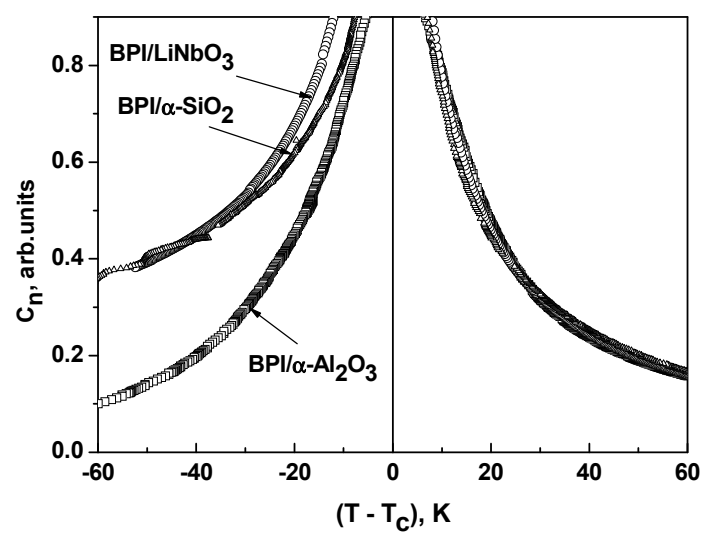

Fig. 17. Temperature dependences of the normalized capacitance of BPI based structures grown on noncentrosymmetric $\mathrm{LiNbO}_{3}$ and $\mathrm{a}-\mathrm{SiO}_{2}$ substrates and on a centrosymmetric a$\mathrm{Al}_{2} \mathrm{O}_{3}$ substrate (Balashova et al., 2011a).

\section{Small signal dielectric response in DBPI films}

The temperature dependences of the capacitance and dielectric losses in the as grown structure obtained from a solution of BPI single crystal in $\mathrm{D}_{2} \mathrm{O}$ on an $\mathrm{NdGaO}_{3}$ substrate are shown in Fig. 18. The phase transition temperature of the initial BPI single crystals used to grow the film was $T_{c} \approx 200 \mathrm{~K}$. The recrystallization of BPI from a solution in heavy water leads to an increase in $\mathrm{T}_{\mathrm{c}}$ by $20 \mathrm{~K}$, which corresponds to a degree of deuteration of about $20 \%$. Analogously to the $\mathrm{BPI} / \mathrm{a}-\mathrm{Al}_{2} \mathrm{O}_{3}$ structure, there is the dispersion of capacitance and tano in the ferroelectric phase of the DBPI/ $\mathrm{NdGaO}_{3}$ structure, which is indicative of the contribution that domain walls make to the dielectric relaxation. A fast decrease in the capacitance with a decrease in temperature below $\mathrm{T}_{\mathrm{c}}$ is observed for both DBPI/NdGaO and $\mathrm{BPI} / \mathrm{a}-\mathrm{Al}_{2} \mathrm{O}_{3}$ structures.
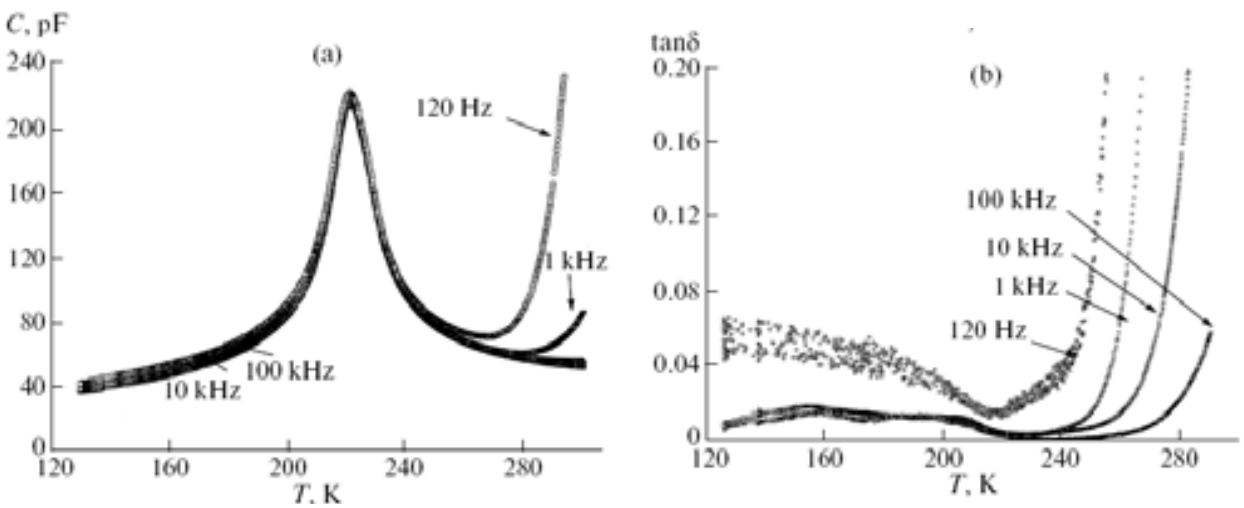

Fig. 18. Temperature dependences of the capacitance (a) and tan $\delta$ (b) for the DBPI/NdGaO 3 structure (Balashova et al., 2011a). 
Figure 19 shows the temperature dependences of the capacitance of the structures grown from a solution of DBPI crystals (obtained by the recrystallization of BPI in heavy water) in $\mathrm{D}_{2} \mathrm{O}$. The permittivity peak for these structures is in the temperature range of $270-285 \mathrm{~K}$, which corresponds to the degree of deuteration $80-90 \%$. In comparison with the BPI-based samples, the capacitance anomaly is significantly broadened in these structures, which is especially pronounced for the film grown on an $\mathrm{a}-\mathrm{Al}_{2} \mathrm{O}_{3}$ substrate. This broadening can be caused by the nonuniform distribution of the degree of deuteration in the film, which should diffuse the phase transition. The difference in the heights of capacitance peaks for the structures shown in Fig. 19 is due to the different orientations of the polar axes in blocks with respect to the normal to the direction of interdigital electrodes and with some differences in film thickness.

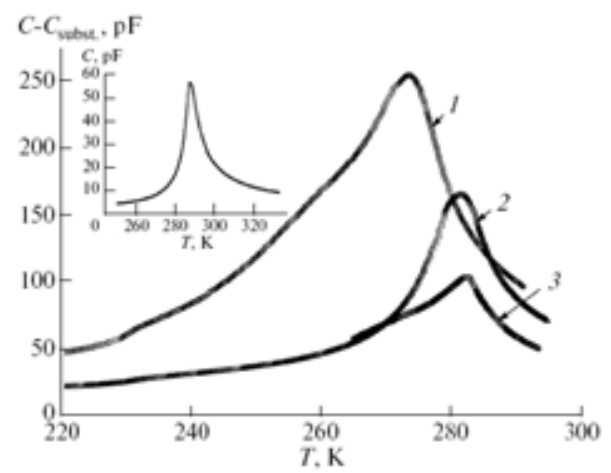

Fig. 19. Temperature dependences of the capacitance introduced into the structure by the DBPI film ( $\left.\mathrm{C}-\mathrm{C}_{\text {substr }}\right)$, measured at $\mathrm{f}=100 \mathrm{kHz}$, in DBPI-based structures on different substrates: (1) a- $\mathrm{Al}_{2} \mathrm{O}_{3},(2) \mathrm{SiO}_{2}$, and (3) $\mathrm{NdGaO}_{3}$. The inset shows the temperature dependence of the capacitance in the initial DBPI crystal (Balashova et al., 2011a).

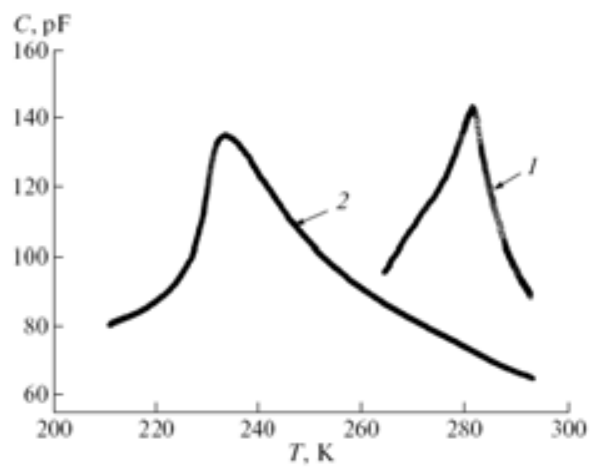

Fig. 20. Temperature dependences of the capacitance for the DBPI/ $\mathrm{NdGaO}_{3}$ structure measured (1) immediately after preparation and (2) after a month (Balashova et al., 2011a).

The structures based on highly deuterated DBPI are less stable than the BPI-based structures. This manifests itself in a slow decrease in the transition temperature of these 
structures with time. Figure 20 shows the temperature dependences of the capacitance of the $\mathrm{DBPI} / \mathrm{NdGaO}_{3}$ structure measured at $\mathrm{f}=100 \mathrm{kHz}$ immediately after the growth and a month later. The relatively narrow capacitance peak at $T=282 \mathrm{~K}$ observed in the as-grown structure is transformed into a diffuse anomaly with a maximum at $T=233 \mathrm{~K}$. This indicates that very slow changes occur in the film structure which are absent in the bulk DBPI crystals. One suggests that this behavior is caused by a gradual decrease in the deuterium concentration in the film due to the diffusion induced replacement of deuterium with protons from the environment.

A study of variation of the dielectric anomaly in DBPI/ $\mathrm{NdGaO}_{3}$ structures with time has shown that the position of capacitance maximum gradually decreases in the temperature scale. This is followed by a variable broadening the dielectric anomaly. Figure 21 presents (a) the temperature $T_{\max }$ corresponding to maximum of capacitance, and (b) maximal value of capacitance $C_{\max }$ and width $W$ of dielectric anomaly ( $W$ is a temperature interval in which $\mathrm{C}(\mathrm{T})-\mathrm{C}_{\text {sub }}$ exceeds $\left(\mathrm{C}_{\max }-\mathrm{C}_{\text {sub }}\right) / 2$ ) versus time $\mathrm{t}$ (in days) after preparation of the structure.
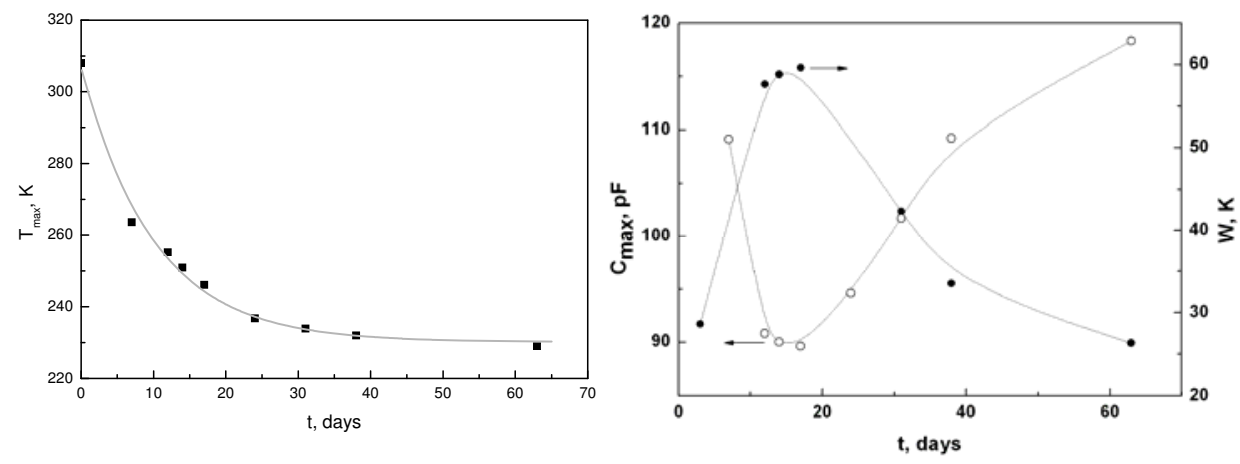

Fig. 21. (a) Time dependence of the temperature $\mathrm{T}_{\max }$ corresponding to maximal capacitance $\mathrm{C}_{\max }$ and (b) time dependence of $\mathrm{C}_{\max }$ and width $\mathrm{W}$ of dielectric anomaly on $\mathrm{DBPI} / \mathrm{NdGaO}_{3}$ structure.

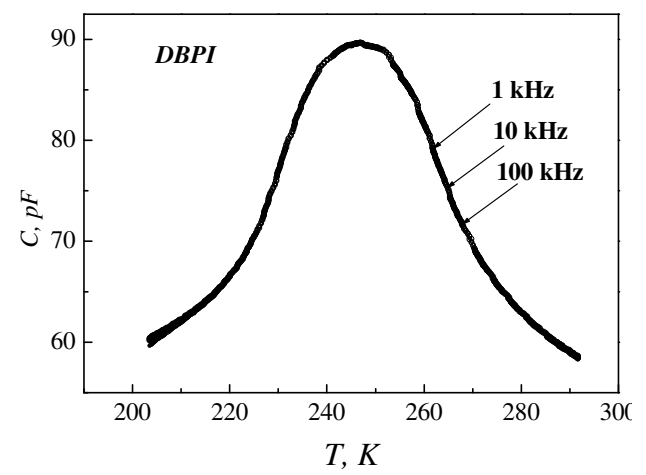

Fig. 22. Temperature dependence of capacity in $\mathrm{DBPI} / \mathrm{NdGaO}_{3}$ structure measured in 12 days after preparation at different frequencies. 
Time dependence of $T_{\max }$ can be well approximated by exponential function $T_{m}=T_{c}($ bulk) $\Delta \mathrm{T}[1-\exp (-\mathrm{t} / \tau)]$, where $\mathrm{T}_{\mathrm{c}}($ bulk $)=308 \mathrm{~K}$ is the phase transition temperature for bulk DBPI crystals used for preparation of film, $\Delta \mathrm{T}=77 \mathrm{~K}$, and $\tau \approx 10$ days. The width of dielectric anomaly $\mathrm{W}$ shows their maximal value after 12 days after preparation and much lower values for $\mathrm{t}=7$ and 63 days. In contrast to that $\mathrm{C}_{\max }$ has their minimal value at $\mathrm{t}=12$ days. It is worth noting that the broadening of dielectric anomaly is not accompanied by dispersion of capacity and appearance of dielectric losses. Fig. 22 shows the temperature dependence of capacity measured on different frequencies in $\mathrm{t}=12$ days after preparation when maximal broadening of dielectric anomaly has been observed. The absence of frequency dispersion proves that the broadening of dielectric anomaly is not related with appearance in films of "relaxors" as it takes place in the case of "diffused" phase transitions (Cross, 1987).

The gradual lowering of the transition temperature $T_{c}$ and variable broadening of dielectric anomaly indicate that the crystal structure of film remains unchanged with time but the concentration and distribution of deuterium and hydrogen ions in the crystal structure is time dependent. This can happens due to substitution of deuterium ions $\mathrm{D}^{+}$by hydrogen ions $\mathrm{H}^{+}$from the environment on the surface of film and interdiffusion of $\mathrm{H}^{+}$ and $\mathrm{D}^{+}$ions inside the film. Note that interdiffusion of $\mathrm{D}^{+}$and $\mathrm{H}^{+}$should go between crystallographic positions in which these ions link the tetrahedra $\mathrm{HPO}_{3}$ by hydrogen bonds because ions in these positions are responsible for the temperature of phase transition. As a result the distribution of deuterium (hydrogen) ions in a film depends on time and is non-uniform along film thickness. The concentration of $\mathrm{D}^{+}$ions is changed with time from the case of totally deuterated film just after the crystallization to the case of DBPI film with small deuteration degree $\left(\mathrm{T}_{\mathrm{c}} \approx 230 \mathrm{~K}, \mathrm{D} \approx 20 \%\right)$. The speed of this process depends on parameters describing the substitution $\mathrm{H}^{+} \rightarrow \mathrm{D}^{+}$on the surface and interdiffusion $\mathrm{H}^{+} \leftrightarrow \mathrm{D}^{+}$inside of film.

The non-uniform distribution of $\mathrm{D}^{+}$ions results in distribution of phase transition temperature inside of film. For this reason different regions of the film differently contribute to total capacity $C$ of the structure. Minimal value of $W$ are observed for $t=63$ days that is close to $\mathrm{W}$ value in BPI films. This indicates that after two months the DBPI film has uniform (or very close to uniform) distribution of deuterium ions (and also $\mathrm{T}_{\mathrm{c}}$ ). Maximal broadening of dielectric anomaly suggest the biggest dispersion of deuterinm concentration in the film. Comparing the maximal and minimal values of $\mathrm{W}$ we can estimate the temperature interval $\Delta \mathrm{T}_{1}$ in which phase transition temperatures $\mathrm{T}_{\mathrm{c}}$ of different regions of film are distributed $\Delta \mathrm{T}_{1}=\mathrm{W}_{\max }-\mathrm{W}_{\min } \approx 30 \mathrm{~K}$. This corresponds to distribution of the deuteration degree in different regions of the film from $30 \%$ up to $60 \%$.

\section{Small signal dielectric response in TGS films}

The dielectric properties of TGS films grown on $\mathrm{Al} / \mathrm{SiO}_{2}$ were studied in the direction normal to the film plane. For this purpose, a silver electrode was pasted onto the upper surface of the film. An aluminum layer served as the bottom electrode. The dielectric properties of TGS films on $\mathrm{a}-\mathrm{Al}_{2} \mathrm{O}_{3}$ substrates were studied in the film plane. We measured temperature dependences of the capacity and loss tangent of the interdigitated structure following film deposition.

Figure 23 displays temperature dependences of the capacity and loss tangent in TGS/Al/ $\mathrm{SiO}_{2}$ (a) and TGS/ $\mathrm{a}-\mathrm{Al}_{2} \mathrm{O}_{3}$ (b) films measured on different frequencies within a 
range of $0.12-100 \mathrm{kHz}$. In both cases, the behavior of the capacity with temperature passes through maxima at the ferroelectric transition point in a bulk crystal $\mathrm{T}_{\mathrm{c}}=322 \mathrm{~K}$. In films on $\mathrm{Al} / \mathrm{SiO}_{2}$, the capacity at its maximum measured at $100 \mathrm{kHz}$ increases about threefold compared with that at room temperature. The capacity of the interdigital structure on a$\mathrm{Al}_{2} \mathrm{O}_{3}$ substrates measured without a TGS film was about $19 \mathrm{pF}$ at room temperature and increased with the film in place by about $3 \mathrm{pF}$. Because the permittivity of the substrate depends only weakly on temperature, the increase of the capacity of the structure should be assigned to the increase of the film permittivity. The capacity of TGS/ $\mathrm{a}-\mathrm{Al}_{2} \mathrm{O}_{3}$ films measured with the interdigital structure at its maximum at $\mathrm{T}=322 \mathrm{~K}$ was found to exceed about sevenfold that at room temperature.
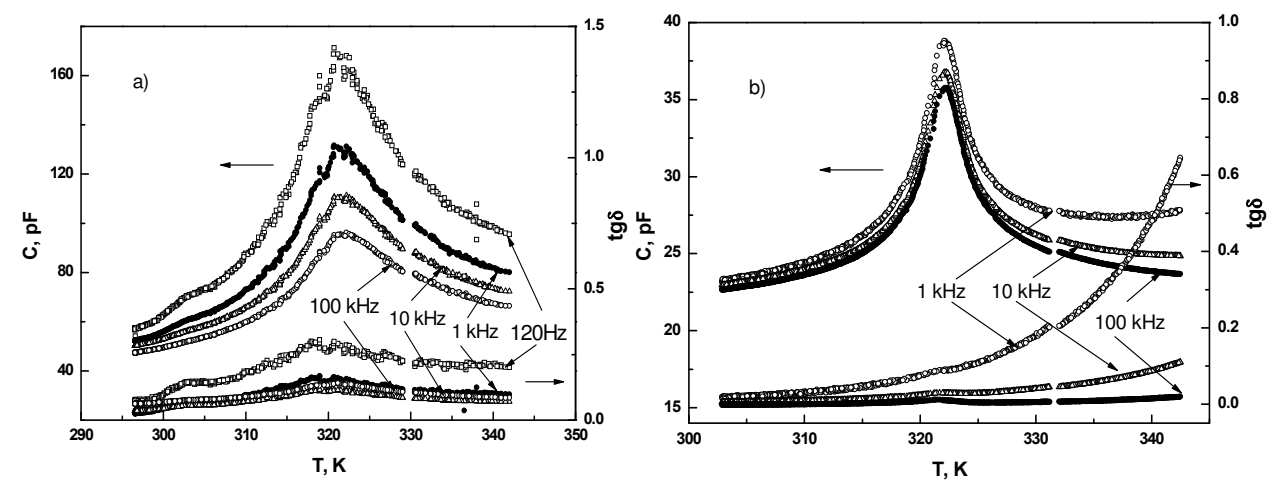

Fig. 23. Temperature dependences of the capacity and tand of TGS films grown on substrates of (a) $\mathrm{Al} / \mathrm{SiO}_{2}$ and (b) $\mathrm{Al}_{2} \mathrm{O}_{3}$ and studied at different frequencies (Balashova et al.,2010).

The maximum permittivity of films on an $\mathrm{Al} / \mathrm{SiO}_{2}$ substrate did not exceed $\varepsilon \approx 100$ whereas in bulk crystals used to grow the films the permittivity measured along the polar axis was $\varepsilon$ $\approx 2000$. This suggests that the fraction of crystallites with the polar axes oriented perpendicular to the film plane is relatively small. The permittivity of TGS/ $\mathrm{a}-\mathrm{Al}_{2} \mathrm{O}_{3}$ films turned out to be substantially larger, $\varepsilon \approx 1000$. This suggests strongly that the polar axis orientation in TGS crystallites is close to the direction orthogonal to the interdigitated electrodes. The permittivity of the films was calculated with the use of the relation (3). The total capacity of the interdigitated structure is found as the product of $\mathrm{C}_{0}$ by the number of electrode pairs $\mathrm{N}$.

$$
\mathrm{C}=\left(\frac{\pi^{3} \mathrm{wN} \varepsilon_{0}}{32}\right)\left\{1+9.5+\left(6.5 \varepsilon_{\mathrm{xx}}\right)^{0.5} \tanh \left[\frac{2 \pi \mathrm{h}}{\lambda}\left(\frac{\varepsilon_{\mathrm{xx}}}{6.5}\right)^{0.5}\right]\right\}
$$

where $\varepsilon_{0}$ is the permittivity of vacuum, $\mathrm{N}=35$, w $=6 \cdot 10^{-3} \mathrm{~m}, \varepsilon_{\mathrm{p}}{ }^{\mathrm{I}}(T) \approx\left(\varepsilon_{\mathrm{xx}}(\mathrm{T}) \varepsilon_{z z}\right)^{0.5}$, assuming $\varepsilon_{z z} \approx 6.5$ to be temperature independent. Calculations yield $19.3 \mathrm{pF}$ for the capacity of an interdigitated structure on white sapphire without a TGS film $(\mathrm{h}=0)$, in full agreement with experiment. To calculate the capacity of an interdigitated structure with the film in place, we substituted in Eq. (14) the experimental temperature dependences of permittivity along the polar axis of the bulk TGS crystals used in film preparation. The Curie-Weiss constant of the crystals was $C_{+}=3500 \mathrm{~K}$, and the relative permittivity at the maximum $\varepsilon=$ 
2000. In calculations using Eq. (14), the film thickness $h$ served as a fitting parameter. The results of the calculations are confronted in Fig. 24 with the experimental relation for the capacity of an interdigital structure coated by a TGS film. The experimental temperature dependences of the capacity of the structure measured at $100 \mathrm{kHz}$ were found to fit the calculated values for an average film thickness $h_{m}=0.2 \mu \mathrm{m}$. The excess of the experimental over calculated values of the capacity of the structure in ferroelectric phase can tentatively be assigned to the contributions of domain wall motion to the permittivity of a film and a bulk crystal being different.

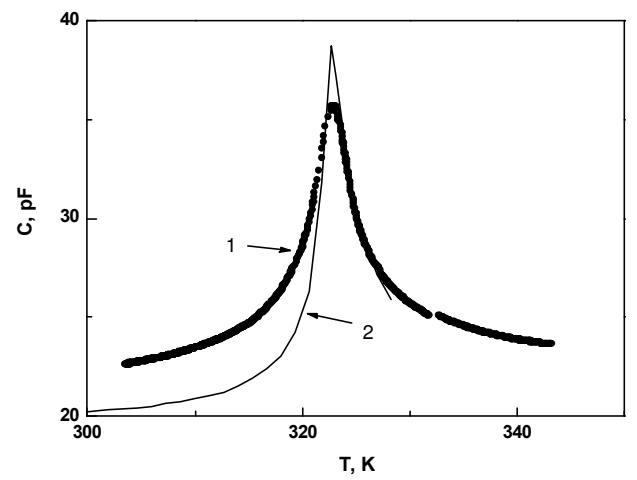

Fig. 24. (1) Experimental and (2) calculated temperature dependences of the capacity of the TGS/a- $\mathrm{Al}_{2} \mathrm{O}_{3}$ structure. The calculation was performed for the case of the film polar axis perpendicular to the electrodes of the interdigital structure (Balashova et al.,2010).
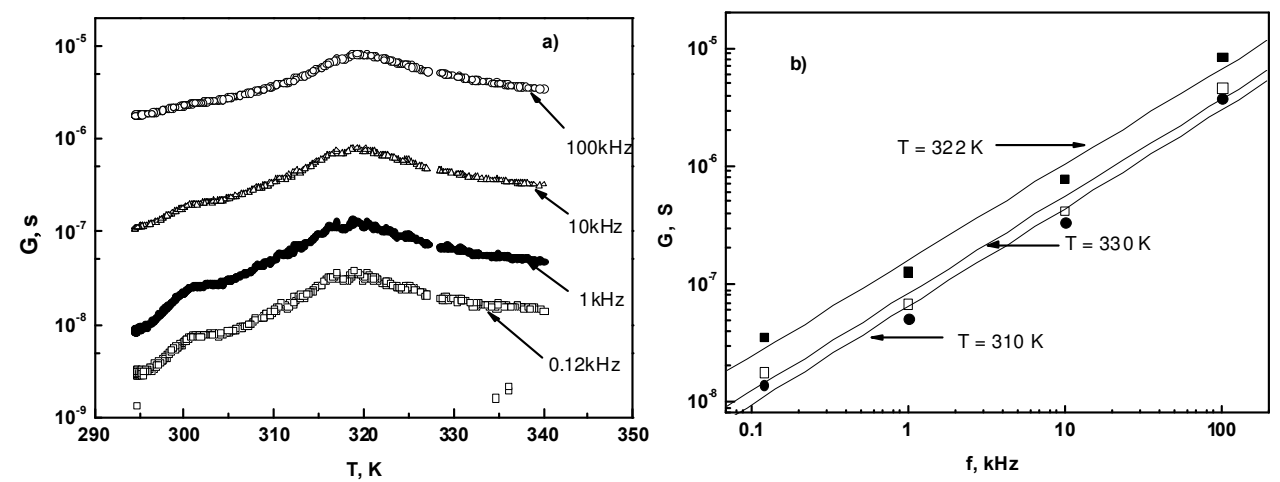

Fig. 25. (a) Temperature dependences of the conductivity on a semilogarithmic scale and (b) frequency dependences of the conductivity on a double logarithmic scale obtained at different temperatures for TGS/ $\mathrm{Al} / \mathrm{SiO} 2$ films (Balashova et al.,2010).

In TGS films on an $\mathrm{Al} / \mathrm{SiO}_{2}$ substrate, the maximum values of tan $\delta$ are observed in the region of the maximum in capacity. By contrast, in TGS/ a- $\mathrm{Al}_{2} \mathrm{O}_{3}$ films one found in this region weak anomalies in tan $\delta$ which become manifest against a strong growth of losses with increasing temperature. A similar behavior of tan $\delta$ with temperature at different frequencies was observed also in films of betaine phosphite (BPI) grown on $\mathrm{LiNbO}_{3}$ 
substrates (Fig.13b). The temperature dependences of permittivity and $\tan \delta$ in $\mathrm{TGS} / \mathrm{Al} / \mathrm{SiO}_{2}$ and TGS/ $\mathrm{a}-\mathrm{Al}_{2} \mathrm{O}_{3}$ films reveal frequency dispersion in the frequency and temperature intervals studied (Fig. 23). To analyze the nature of this dispersion, calculations of the conductivity $G=\omega C \tan \delta$, where $\omega$ is circular frequency, and $C$, the film capacity, were performed.
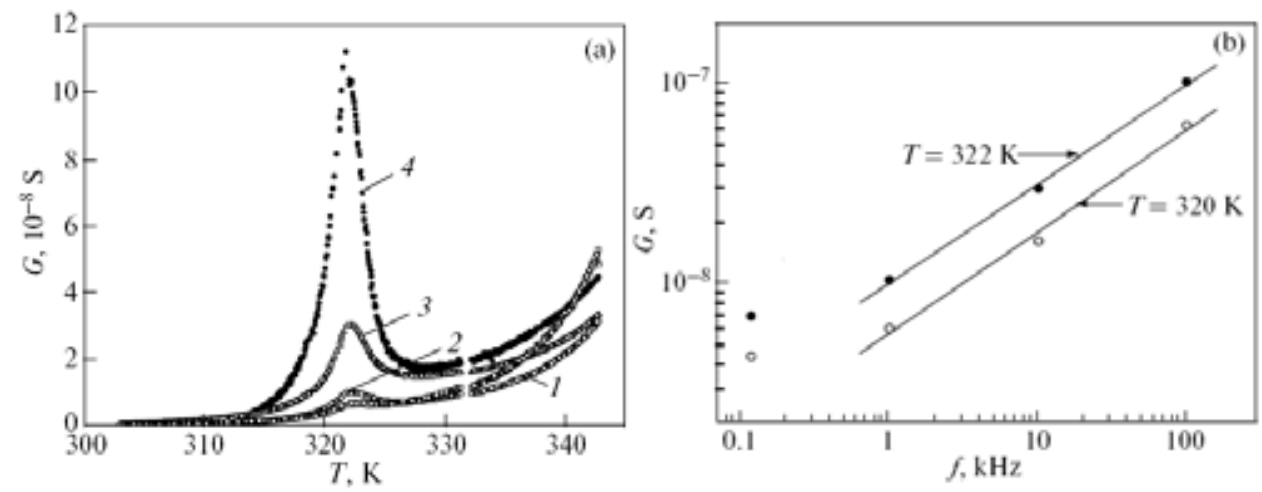

Fig. 26. (a) Temperature dependences of the conductivity in TGS/ $\mathrm{a}-\mathrm{Al}_{2} \mathrm{O}_{3}$ films obtained at frequencies of (1) 0.12 , (2) 1, (3) 10, and (4) $100 \mathrm{kHz}$. (b) frequency dependences of the conductivity on a double logarithmic scale obtained for two temperatures (Balashova et al.,2010).

Figure 25a plots temperature dependences of the conductivity $G$, and Fig. 25b, frequency dependences of the conductivity of $\mathrm{TGS} / \mathrm{Al} / \mathrm{SiO}_{2}$ for three temperatures. In the lowfrequency region $(\mathrm{f}<1 \mathrm{MHz}$ ), the film conductivity can be mediated by $\mathrm{dc}$ and ac conductivity: $G(\omega)=G_{d c}+G_{a c}$, where $G_{d c}$ is the frequency-independent dc conductivity, and $\mathrm{G}_{\mathrm{ac}}=\mathrm{A} \omega^{\mathrm{s}}(\mathrm{s} \leq 1)$, the frequency dependent ac conductivity (Pike, 1972). The straight lines in Fig. $25 \mathrm{~b}$ suggest that in $\mathrm{TGS} / \mathrm{Al} / \mathrm{SiO}_{2}$ films the dc conductivity contributes very little, the main contribution being provided by the ac conductivity $\mathrm{G}_{\mathrm{ac}}$. The frequency dependences of the ac conductivity (Fig. $25 b$ ) permit determination of the parameter $s \approx 0.82$. The deviation of the frequency dependence of the ac conductivity from a linear course $(s=1)$ signals a manifestation of specific conductivity mechanisms. The most plausible of them appears to be hopping charge transport between localized states separated by an energy barrier. The theoretical model of such a conductivity considered in (Pike, 1972) allows for carrier hopping between barrier-separated states distributed randomly in the bulk of the sample. This model was successfully used to describe the low-frequency conductivity in thin films of scandium oxide (Pike, 1972), as well as in betaine phosphate crystals with a $5 \%$ addition of BPI (Huttun et al. 1991). The value of the $s$ parameter in the frequency dependence of ac conductivity permits one to estimate the energy difference between the ground state at the energy minimum and the free state in which a carrier can travel over the lattice, $\mathrm{W}_{\mathrm{m}}=$ $6 \mathrm{kT} /(1-\mathrm{s})$. Calculations yield $\mathrm{W}_{\mathrm{m}} \sim 0.9 \mathrm{eV}$ for the TGS/ $\mathrm{Al} / \mathrm{SiO}_{2}$ structure. The values of $\mathrm{W}_{\mathrm{m}}$ and $\varepsilon$ can now be used to determine the Bohr radius of a localized carrier, $\mathrm{a} \approx \mathrm{e}^{2} / 2 \varepsilon \mathrm{W}_{\mathrm{m}} \approx$ 10 A that is close to the TGS lattice parameter.

The temperature and frequency plots of conductivity in the TGS/ $\mathrm{a}-\mathrm{Al}_{2} \mathrm{O}_{3}$ structures displayed in Fig. 26 differ noticeably from those for TGS/ Al $/ \mathrm{SiO}_{2}$. In TGS/ $\mathrm{a}-\mathrm{Al}_{2} \mathrm{O}_{3}$ films, at temperatures above $(T>325 \mathrm{~K})$ and below $(T<315 \mathrm{~K})$ the phase transition point $\mathrm{T}_{\mathrm{c}}=322 \mathrm{~K}$ 


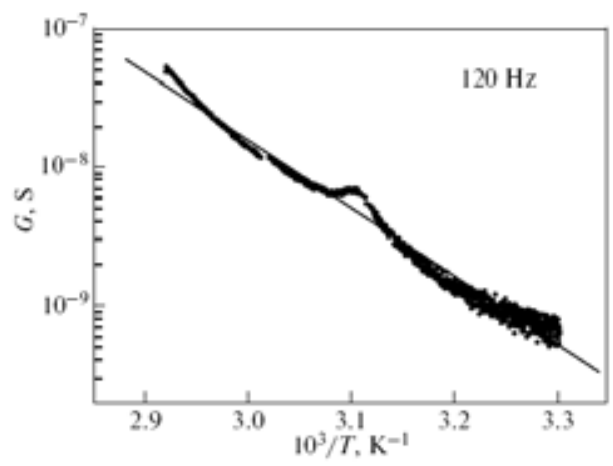

Fig. 27. Temperature dependence of the conductivity in TGS/a- $\mathrm{Al}_{2} \mathrm{O}_{3}$ films at $f=120 \mathrm{~Hz}$ (Balashova et al.,2010).

the frequency dependence of conductivity is fairly weak, so that the temperature dependences of conductivity drawn for different frequencies practically coincide (Fig. 26a). This suggests that within these temperature regions the dominant contribution comes from dc conductivity mediated by thermally activated diffusion. Around the phase transition point, $315<\mathrm{T}<325 \mathrm{~K}$, however, an additional contribution to conductivity appears that displays strong dispersion (Fig. 26a). The frequency difference of conductivity in the vicinity of the phase transition is shown graphically for two temperatures in Fig. 26b. Above $f=1$ $\mathrm{kHz}$, this relation is linear with a slope $\mathrm{s} \approx 0.5$. In the low-frequency domain, $\mathrm{f}<1 \mathrm{kHz}$, the conductivity is seen to depend very weakly on frequency. This suggests that it is dominated by dc conductivity. Figure 27 plots the temperature dependence of conductivity for $\mathrm{f}=120$ $\mathrm{Hz}$ drawn on a log-normal scale. The activation energy estimated from this slope is $\mathrm{E}_{\mathrm{a}} \approx 0.9-$ $1 \mathrm{eV}$. The same value of activation energy was obtained for DTGS crystals (Shilnikov et al., 2001). As follows from Fig. 27, near the phase transition conductivity passes through a small maximum. A similar maximum in conductivity at frequencies of 1-10 Hz was observed in DTGS single crystals (Shilnikov et al., 2001). Significantly, the activation energy $\mathrm{E}_{\mathrm{a}} \approx 0.9-1 \mathrm{eV}$ in TGS films exceeds by about an order of magnitude that observed in BPI films $\left(\mathrm{E}_{\mathrm{a}} \approx 0.1 \mathrm{eV}\right)$ grown by evaporation on $\mathrm{LiNbO}_{3}(\mathrm{Y})$ and $\mathrm{a}-\mathrm{SiO}_{2}(\mathrm{Z})$ substrates. The manifestation of ac conductivity in the temperature interval $315<\mathrm{T}<325 \mathrm{~K}$ suggests operation of an additional conductivity mechanism near the phase transition that was absent far from $\mathrm{T}_{\mathrm{c}}$. Viewed in the context of the hopping conduction model (Pike, 1972), this could signal formation of barriers and a decrease in the degree of carrier localization in the phase transition region. Note, however, that if the potentials are of the Coulomb type $(\mathrm{V} \sim 1 / \varepsilon \mathrm{r}$, where $\mathrm{r}$ is the distance from the local center to the carrier), the degree of carrier localization in this temperature interval should increase rather than decrease. Because close to $T_{c}$ permittivity grows, the Coulomb potentials localizing the carriers become more narrow, thus reducing the potential overlap between neighboring centers. Whence it follows that the ac conductivity becoming manifest in the vicinity of $T_{c}$ is not associated with hopping conduction and is rather determined by other mechanisms. Studies of TGS crystals revealed the existence within a narrow temperature interval close to $\mathrm{T}_{\mathrm{c}}$ of a low-frequency relaxation contribution to permittivity whose magnitude is very sensitive to the presence of defects and to the crystal quality. The most probable mechanism of this contribution, as well as of the ac conductivity near $\mathrm{T}_{\mathrm{c}}$ in TGS/ $\mathrm{a}-\mathrm{Al}_{2} \mathrm{O}_{3}$ structures, is the motion of domain walls or small-radius domain 
nuclei, which contribute noticeably to permittivity and mediate the low-frequency dielectric dispersion near the phase transition (Pawlaczyk, 1993).

\section{Strong signal dielectric response in DBPI films}

Strong signal dielectric response (dielectric hysteresis loops) was investigated by means of Sawyer-Tower method in the temperature range $\mathrm{T}=(120-340) \mathrm{K}$ and frequency range $\mathrm{f}=$ $(0.06-3) \mathrm{kHz}$. AC voltage with amplitude of $\mathrm{U}_{\mathrm{E}} \approx 100 \mathrm{~V}$ (that corresponds to electric field of $\mathrm{E} \approx 2 * 10^{6} \mathrm{~V} / \mathrm{m}$ between electrodes), was applied to electrodes of IDS, and the voltage $\mathrm{U}_{\mathrm{p}}$ proportional to polarization between electrodes was measured from the capacitance $C=0.3$ $\mu$ F included in series with the IDS.

Here we present the results of investigation of strong signal dielectric response in DBPI films with small deuteration degree $\sim 20 \%\left(\mathrm{~T}_{\mathrm{c}} \approx 227 \mathrm{~K}\right)$ consisting of one single crystal block (Balashova et al. 2011b). Dielectric loops in films with high degree of deuteration ( 80\%) will be published elsewhere. Fig. 28 shows the dependence of $U_{p}$ on $U_{E}$ at frequency $f=250$ $\mathrm{Hz}$ for different temperatures. In paraelectric region at $\mathrm{T}>240 \mathrm{~K}$ a dependence $\mathrm{U}_{\mathrm{P}}\left(\mathrm{U}_{\mathrm{E}}\right)$ is linear and the structure represents a linear dielectric. In vicinity of $T_{c}$ the dependence $\mathrm{U}_{\mathrm{P}}\left(\mathrm{U}_{\mathrm{E}}\right)$ is nonlinear and at $\mathrm{T}<\mathrm{T}_{\mathrm{c}}$ hysteresis loops appear.

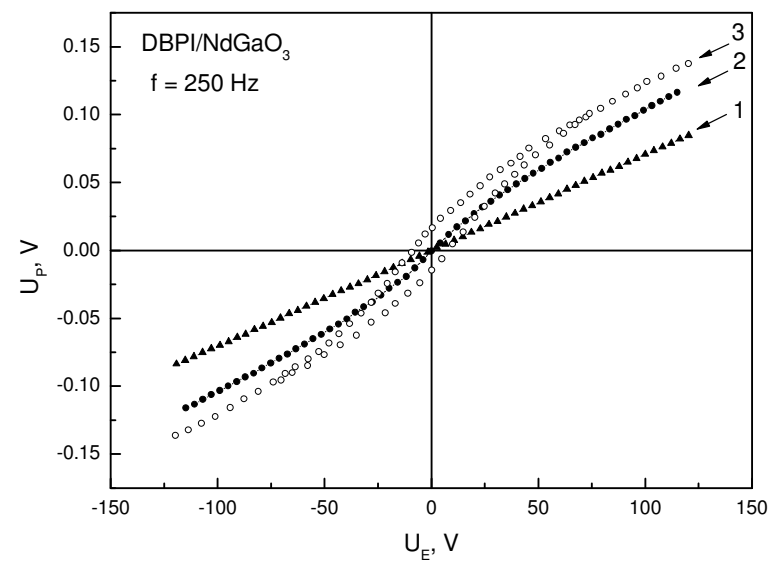

Fig. 28. $\mathrm{U}_{\mathrm{p}}\left(\mathrm{U}_{\mathrm{E}}\right)$ dependence in $\mathrm{DBPI} / \mathrm{NdGaO}_{3}$ structure at $\mathrm{f}=250 \mathrm{~Hz}$ for three temperatures 1 - 258 K, 2- 232 K, 3 - 155 K (Balashova et al., 2011b).

Hysteresis loops, obtained after subtraction of linear dependence $U_{P}\left(U_{E}\right)$ which is observed for large values of $U_{E}$ when the structure is in saturation, for different frequencies at $T=192$ $\mathrm{K}$ and $\mathrm{T}=144 \mathrm{~K}$ (below $\mathrm{T}_{\mathrm{c}}=227 \mathrm{~K}$ ) are shown in Fig. 29. For low frequencies $\mathrm{f} \sim(0.06-0.1)$ $\mathrm{kHz}$ the hysteresis loops are very narrow. The width of loops considerably increases with frequency and for $\mathrm{f} \sim(2.5-3) \mathrm{kHz}$ very wide loops are observed.

Fig. 30 shows the temperature dependence of magnitude of $U_{p}$ voltage in saturated state of the film $\left(U_{P^{s}}\right)$. The $U_{P^{s}}(T)$ does not depend on frequency. Non-zero values of $U_{P^{s}}$ in the region $\mathrm{T}_{\mathrm{c}}<\mathrm{T}<240 \mathrm{~K}$ are related with dielectric non-linearity of ferroelectrics above the phase transition temperature. Below $T_{c}$ the temperature dependence of $U_{P}{ }^{s}$ is analogous to one of spontaneous polarization $\mathrm{P}_{\mathrm{s}}$. 

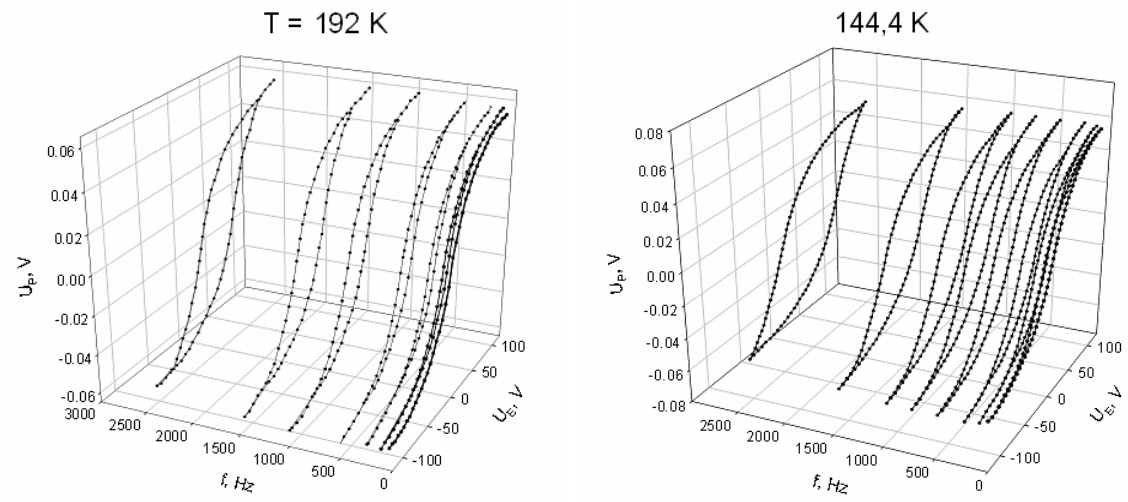

Fig. 29. Hysteresis loops in $\mathrm{DBPI} / \mathrm{NdGaO}_{3}$ structure for different frequencies at $\mathrm{T}=182 \mathrm{~K}$ and 144.4 K (Balashova et al., 2011b).

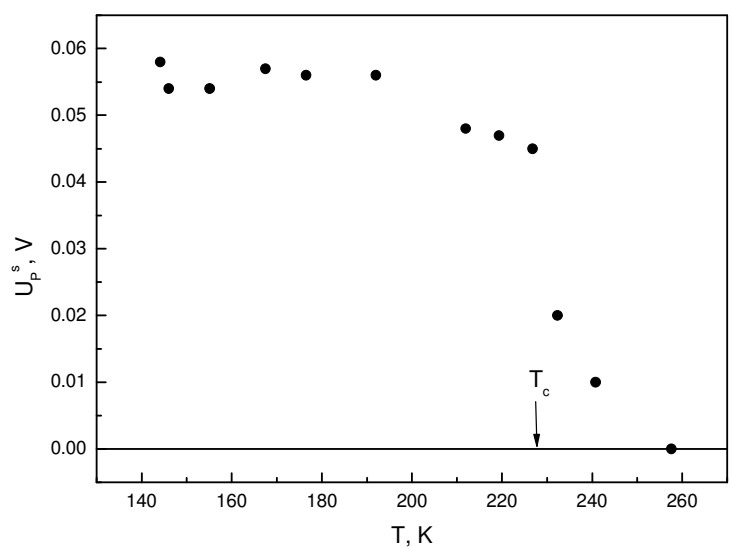

Fig. 30. Temperature dependence of $\mathrm{U}_{\mathrm{P}} \mathrm{s}$ in $\mathrm{DBPI} / \mathrm{NdGaO}_{3}$ structure (Balashova et al., 2011b).

Fig.31 presents the temperature dependence of remnant voltage $U_{P^{r}}\left(U_{P^{r}}=U_{P}\right.$ at $\left.U_{E}=0\right)$ for different frequencies (a) and frequency dependence of $U_{P^{r}}$ for different temperatures (b). In contrast to $U_{P^{s}}$ the remnant voltage exhibits strong frequency dispersion. The magnitude of $\mathrm{U}_{\mathrm{P}}{ }^{\mathrm{r}}$ increases with frequency. Opening the loop takes place at a temperature $\mathrm{T}_{\mathrm{op}}$ which depends on the frequency $\mathrm{f}$. For $\mathrm{f}=60 \mathrm{~Hz}$ and $\mathrm{f}=120 \mathrm{~Hz}$ the non-zero values of $\mathrm{U}_{\mathrm{P}}{ }^{\mathrm{r}}$ are observed for $\mathrm{T}<180 \mathrm{~K}$ and $\mathrm{T}<220 \mathrm{~K}$ correspondingly. At the further increase in frequency $\mathrm{T}_{\text {op }}$ increases up to $\mathrm{T}_{\mathrm{op}}=240 \mathrm{~K}$ for $\mathrm{f}=3 \mathrm{kHz}$.

Strong signal dielectric response in DBPI/IDS/substrate structures is principally different from that observed in ferroelectric single crystals with use of plane parallel capacitance geometry. It is well known that in the last case the most wide dielectric loops are observed for the lowest frequencies. An increase of frequency results in gradual narrowing and disappearance of the loop (Tagantsev et al. 2010). We have observed this effect in bulk DBPI 
samples. In structures under study a situation is absolutely opposite - the loop aria is increased with frequency (Fig. 29). The difference in frequency behavior is related with difference of saturated states of uniaxial ferroelectric in the case of plane parallel capacitance and IDS structure. In the first case the saturated state is a single domain state which appears at $U_{E}=U_{E} s$ Fig. 32a,b). This state remains at reduction of $U_{P}$ to zero because the depolarizing fields are compensated by charges on electrodes. When $U_{E}$ is reversed a polarization switching takes place. This process begins with appearance of the nucleus with reversed polarization and following movement of domain walls. The situation is quite different in the case of IDS. Let us consider an uniaxial ferroelectric film which which polar axis is orthogonal to the electrodes of IDS. In this case a saturated state at $U_{E}=U_{E} s$ is multidomain state consisting of stripe domains type "head-to head" (Fig.32c). At $\mathrm{U}_{\mathrm{E}}=-\mathrm{U}_{\mathrm{E}} \mathrm{s}$ the saturated state also consists on stripe domains with opposite direction of polarization in stripes (Fig. 32d). Because the saturated state is multidomain the transition from one configuration of domains to another one can occur by movement of domain walls. Necessity of nucleation of domains with reversed polarization direction thus is absent.
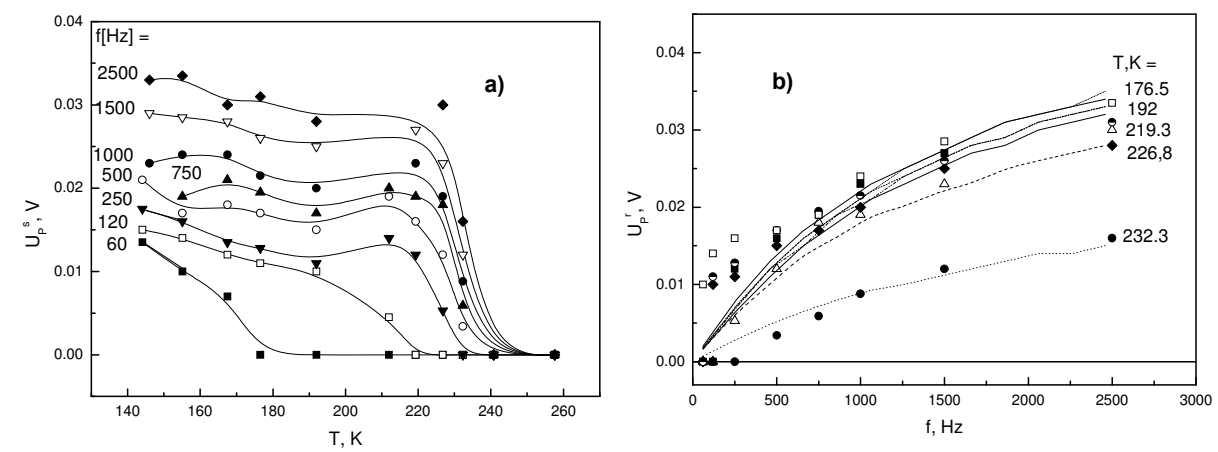

Fig. 31. (a) Temperature dependence of remnant voltage $U_{p} r$ for different frequencies and (b) frequency dependence of $U_{p}{ }^{r}$ for different temperatures (Balashova et al., 2011b).
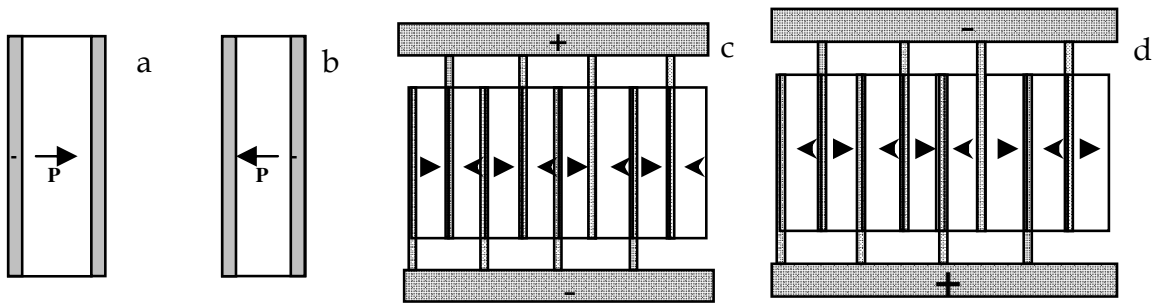

Fig. 32. Schematic image of saturated states of uniaxial ferroelectric in the scheme of plane parallel capacitance $(a, b)$ and planar IDS (c, d) (Balashova et al., 2011b).

It is worth noting that an appearance in ferroelectrics of a system of "head-to head" domains is energetically non-profitable (Strukov \&Levanyuk, 1998). Because in this case the domain walls are charged very strong depolarization fields appear. In IDS structure these fields can partially be compensated due to charges on IDS electrodes but full compensation doesn't arise because of a non-zero thickness of the film. As a result in IDS structure the system of stripe "head-to head" domains aspires to collapse and completely disappears at $\mathrm{U}_{\mathrm{E}}=0$. 
At low frequency of the driving field $U_{E}$ the domain walls are in-time with change of applied field and dielectric hysteresis loops are absent or very narrow. At frequency increase, because the speed of movement of walls is limited, they are behind changes of the field and loops are open. As walls between "head-to head" domains are charged, their movement in electric field is accompanied by charge carrying. It is similar to occurrence in the structure of electric conductivity, however, in this case the conductivity is defined not by free but bonded charges which arise only in ferroelectric state.

Opening of dielectric hysteresis loop with frequency increase can be described if we know nonlinear non-hysteretic dependence $U_{P}\left(U_{E}\right)$ which is observed at low frequency and suppose that at step-like change of $\mathrm{U}_{\mathrm{E}}\left(\mathrm{U}_{\mathrm{E}} \rightarrow \mathrm{U}_{\mathrm{E}}+\Delta \mathrm{U}_{\mathrm{E}}\right)$ at $\mathrm{t}=0$ the voltage $\mathrm{U}_{\mathrm{P}}$ aspires to their equilibrium value $U_{P}\left(U_{E}+\Delta U_{E}\right)$ according to exponential law, i.e. $U_{P}(t)=U_{P}\left(U_{E}\right)+$ $\Delta \mathrm{U}_{\mathrm{P}}[1-\exp (-\mathrm{t} / \tau)]$, where $\Delta \mathrm{U}_{\mathrm{P}}=\mathrm{U}_{\mathrm{P}}\left(\mathrm{U}_{\mathrm{E}}+\Delta \mathrm{U}_{\mathrm{E}}\right)-\mathrm{U}_{\mathrm{P}}\left(\mathrm{U}_{\mathrm{E}}\right)$, and $\tau$ is the relaxation time. In Fig. $31 \mathrm{~b}$ the results of calculation are shown by lines. In calculations the non-hysteretic $\mathrm{U}_{\mathrm{P}}\left(\mathrm{U}_{\mathrm{E}}\right)$ dependence was approximated by Langevin function which describes the nonlinear $U_{P}\left(U_{E}\right)$ dependence for different temperatures with good accuracy. Calculations show that the magnitude of $\tau$ increases with temperature decrease from $\tau \approx 25 \mu$ s at $\mathrm{T} \approx \mathrm{T}_{\mathrm{c}}$ up to $\tau \approx 45$ $\mu$ s at $\mathrm{T}=150 \mathrm{~K}$. It should be noted that considered model though describes basically the behavior $U_{P^{r}}(f)$ and $U_{P^{r}}(T)$ nevertheless is not able to describe these dependences precisely, in particular at low frequencies. In particular, there is opened a question why on frequencies $f=(60-120) \mathrm{Hz}$ the loop opening occurs at temperatures essentially smaller $T_{c}$, unlike higher frequencies at which it occurs at $\mathrm{T} \sim \mathrm{T}_{\mathrm{c}}$ (Fig. 31a). Probably, it is connected with change of character of movement of domain walls at frequency increase.

\section{Conclusions}

Main results of studies presented in this chapter can be summarized as follows. First of all the possibility of growth of amino acid ferroelectric film on different substrates is shown. In contrast to other methods of ferroelectric film preparation the evaporation method does not need use of high substrate temperature and is characterized by relative simplicity and low cost. Films prepared by this method are not epitaxial and for this reason the film growth is not strongly related with a mismatch between substrate and film lattice parameters but is governed mainly by wettability of substrate by water solution. The temperature of ferroelectric phase transition is BPI and TGS films coincides with bulk samples that means that a substrate has no influence on $\mathrm{T}_{\mathrm{c}}$. In spite of the fact that the films are not epitaxial they are strongly connected with substrate and clearly exhibit a film-substrate interaction.

Most of films presented in the chapter are polycrystalline. The only exception is the DBPI film grown on $\mathrm{NdGaO}_{3}$ substrate which consists of one single crystal block. BPI and DBPI films consist of large single crystal blocks which dimensions are varied from 0.1 to several tens of $\mathrm{mm}^{2}$. In contrast to that TGS films consist of blocks with dimensions smaller than 1 $\mathrm{mm}^{2}$. The polar axis in both TGS and BPI (DBPI) films is oriented in-plane of substrate. For this reason a study of dielectric properties of films was carried out by means of IDS of electrodes deposited on substrate.

Main features of dielectric properties of films coincide with bulk samples. All films exhibit pronounced dielectric anomaly at ferroelectric phase transition analogous to bulk crystals, and similar to bulk the values of dielectric permittivity and the electric field effect on dielectric permittivity. At the same time they show also considerable differences. The most pronounced among them is a transformation with time of deuteration degree observed in 
DBPI films. This phenomenon is absent in DBPI crystals. The dielectric anomaly in DBPI films with high degree of deuteration slowly changes with time reflecting changes in distribution of $\mathrm{D}^{+}$ions in the film. This process is caused by substitution of deuterium ions by hydrogen ions on the surface and interdiffusion of these ions inside of the film. We believe that this process can be stopped by covering the film surface by thin dielectric layer. If so it would be a method for preparation films with controlled width of dielectric anomaly. Also it is worth noting a specific temperature behavior of dielectric permittivity below $T_{c}$ in BPI films grown on non-centrosymmetric substrates. In these films in contrast to bulk samples and films grown on centrosymmetric substrates the dielectric anomaly does not exhibit a contribution of domain wall movement.

The possibility to grow films of uniaxial ferroelectrics consisting of large single crystal blocks on IDS structure of electrodes gives rise to observation of specific dielectric hysteresis loops showing very unusual frequency behavior. To the best of our knowledge such very strong increase of remnant voltage and coercive field with frequency has not been observed in ferroelectrics up to now. At low frequency very narrow hysteresis loops with strong nonlinear P-E behavior related with ferroelectric domain wall movement have been found.

It should be noted that the evaporation method has also some disadvantages as compared with epitaxial growth. Up to now it is not possible to control the orientation of film crystal axis in the plane of substrate. In most cases the polar axis in blocks is oriented not far from direction orthogonal to electrodes of IDS and therefore dielectric anomaly is large. Nevertheless in some films the anomaly is not strong showing that projection of polar axis on electrodes is small.

The further investigations of structures based on amino acid ferroelectric films could be related with increase of amino acid ferroelectrics used for preparation of films (glycine phosphite, betaine arsenate and so on), probing of different substrates, and study of acoustic and optical properties of obtained structures.

\section{Acknowledgment}

The authors thanks Prof. Dr. V.V. Lemanov for helpful discussions. This research was partly supported by RFBR (grant 10-02-00557).

\section{References}

Albers, J.; Klöpperpieper, A.; Rother, H.J. \& Haussühl, S. (1988). Ferroelectricity in betaine phosphite, Ferroelectrics, Vol.81, pp. 27-30, ISSN 0015-0193.

Albers, J. (1988). Betaine compounds - a new family with ferroelectric and incommensurate phases, Ferroelectrics, Vol.78, pp. 3-10, ISSN 0015-0193

Balashova, E.V.; Lemanov, V.V.; Tagantsev, A.K.; Sherman, A.B. \& Shomuradov, Sh.H. (1995). Betaine arsenat as a system with two instabilities, Phys.Rev.B, Vol. 51, No.14, pp. 8747-8753, ISSN 1098-0121

Balashova, E. V. \& Lemanov, V. V. (2000). Acoustic and dielectric properties of betaine phosphite and a phenomenological model with coupled order parameters, Ferroelectrics, Vol.247(4), pp. 269-281, ISSN 0015-0193 
Balashova, E. V.; Lemanov, V. V. \& Klöpperpieper A. (2002). Effect of Electric Field on the Dielectric Permittivity of Betaine Phosphite Crystals in the Paraelectric Phase, Phys.Sol.State, Vol.44, No.8, pp. 1597-1603, ISSN 1063-7834

Balashova, E. V. \& Lemanov, V. V. (2003). Dielectric Properties of Betaine Phosphite-Betaine Phosphate Solid-Solution Crystals in the Improper Ferroelastic Phase, Phys.Sol.State, Vol.45, No.7, pp. 1310-1314, ISSN 1063-7834 [Fiz.Tverd.Tela, Vol.45, No.7, pp. 1250-1255]

Balashova, E. V. \& Lemanov, V. V. (2003). Dielectric and Acoustic properties of Some Betaine and Glycine Compounds, Ferroelectrics, Vol.285, pp. 1179-205, ISSN 00150193

Balashova, E.V.; Krichevtsov, B.B.\& Lemanov, V.V. (2008). Ferroelectric betaine phosphite films: Growth, optical imaging, and dielectric properties, J.Appl.Phys. Vol.104, pp.126 104(1-3), ISSN 0021-8979

Balashova E.V.; Krichevtsov B.B. \& Lemanov V.V. (2009). Dielectric properties of betaine phosphite films, Fiz. Tverd. Tela (St. Petersburg), Vol.51, No.3, pp. 525-532 [Phys.Solid State Vol.51, pp. 560-567, ISSN 1063-7834].

Balashova, E.V.; Krichevtsov; B.B. \& Lemanov, V.V. (2009). Growth, optical imaging, and dielectric properties of ferroelectric betaine phosphite and triglycine sulphate films, Integr. Ferroel., Vol.106, pp. 29-39, ISSN 1058-4587

Balashova, E.V.; Krichevtsov, B.B. \& Lemanov, V.V. (2010). Permittivity and Conductivity of Triglycine Sulfate films on $\mathrm{Al} / \mathrm{SiO}_{2}$ and $\alpha-\mathrm{Al}_{2} \mathrm{O}_{3}$ Substrates. Fiz. Tverd. Tela (St. Petersburg) Vol.52, No.1. pp.119-123 [Phys.Solid State Vol.51, No.1, pp.126-131, ISSN 1063-7834].

Balashova, E.V.; Krichevtsov, B.B.; Zaitseva, N.V.; Pankova, G.A.; Frederiks, I.D \& Lemanov, V.V. (2011). Dielectric properties of betaine phosphite and deuterated betaine phosphite films, Crystallography report, Vol.56, No.1, pp. 38-43, ISSN 1063-7745 [Kristallografiya, Vol.56, No.1, pp. 42-47, ISSN 0023-4761]

Balashova, E.V.; Krichevtsov, B.B. \& Lemanov, V.V. (2011). Fiz. Tverd. Tela (St. Petersburg) in press, [Phys.Solid State, in press].

Banys, J.; Sobiestianskas, R.; Völkel, G.; Klimm, C.; Klöpperpieper, A. (1996). Microwave dielectric dipersion in deuterated betaine phosphite, Phys. Status Solidi (a), Vol.155, No.2, pp. 541-545, ISSN 1862-6300

Bauch, H.; Banys, J.; Bötteher, R.; Pöple, A.; Völkel, G.; Klimm, C. \& Klöpperpieper, A. (1995). Structural phase transitions in partially deuterated betaine phosphite studied by dielectric and electron paramagnetic resonance methods, Ferroelectrics, Vol. 163, No 1, pp. 59-68, ISSN 0015-0193

Cross, L.E. (1987). Relaxor ferroelectrics, Ferroelectrics, Vol. 76, No 1, pp. 241-267, ISSN 00150193

Dawber, M; Rabe, K.M. \& Scott, J.F. (2005). Physics of thin-film ferroelectric oxides, Rev. Mod. Phys. Vol. 77, No. 4, pp. 1083 - 1130, ISSN 0034-6861

Ducharme, S.; Palto, S.P. \& Fridkin, V.M. (2002). Ferroelectrics and dielectric thin films, In: Handbook of thin film materials, Vol.3, Chapter 11, Academic Press, San Diego

Fehst, I.; Paasch, M.; Hutton, S.L.; Braune, M.; Böhmer, R.; Loidl, A.; Dörffel, M.; Narz, Th.; Haussühl, S. \& McIntyre, G.J. (1993). Paraelectric and ferroelectric phases of 
betaine phosphite: structural, thermodynamic, and dielectric properties. Ferroelectrics, Vol.138, pp.1-10, ISSN 0015-0193

Fletcher, S.R.; Keve, E.T. \& Skapcki, A.C. (1976). Structural studies of triglycine sulphate part i: low radiation dose (structure a). Ferroelectrics, Vol.14, pp. 775-787, ISSN 0015-0193

Holakovsky, J. (1973). A new type of ferroelectric phase transition, Phys.Stat.Sol. (b), Vol.56, No.2, pp. 615-619, ISSN 0370-1972

Hutton, S.L.; Fehst, I.; Böhmer, R.; Braune M.; Mertz, B.; Lunkenheimer, P.; Loidl, A. (1991). Proton glass behavior and hopping conductivity in solid solutions of antiferroelectric betaine phosphate and ferroelectric betaine phosphite, Phys.Rev.Lett., Vol. 66, No.15 pp. 1990-1993, ISSN 0031-9007

Kino G. S. \& Wagers R. S. (1973). Theory of interdigital couplers on nonpiezoelectric substrates, J. Appl. Phys., Vol.44, No.4, pp. 1480-1488, ISSN 0021-8979

Lal R.B. \& Batra A.K. (1993). Growth and properties of triglycine sulfate (TGS) crystals: Review, Ferroelectrics, Vol.142, pp. 51-82, ISSN 0015-0193

Matthias, B.T.; Miller, C.E. \& Remeika, J.P. (1956). Ferroelectricity of Glycine Sulfate, Phys.Rev., Vol.104, pp.849-850.

Neumann N. (1993). Modified triglycine sulphate for pyroelectric infrared detectors, Ferroelectrics, Vol.142, pp. 83-92, ISSN 0015-0193

Pawlaczuk, Cz. (1993). Domain wall dielectric response in the phase transition region of some ferroelectrics, Ferroelectrics, Vol. 140, No 1, pp. 127-132, ISSN 0015-0193

Pertsev, N.A.; Zembilgotov \& Tagantsev, A.K.(1998). Effect of Mechanical Boundary Conditions on Phase Diagrams of Epitaxial Ferroelectric Thin Films, Phys.Rev.Lett., Vol. 80, No.9, pp. 1988-1991, ISSN 0031-9007

Pike, G.E. (1972). ac Conductivity of scandium oxide and a new hopping model for conductivity, Phys.Rev.B, Vol.6, No4, pp. 1572-1580, ISSN 1098-0121

Schaack G. (1990). Experimental results on phase transitions in betaine compounds, Ferroelectrics, Vol.104, pp. 147-158, ISSN 0015-0193

Shilnikov, A.P.; Pozdnyakov, A.P.; Nesterov, V.N.; Fedorikhin, V.A. \& Shuvalov, L.A. (2001). The contributions from different mechanisms of motion of domain boundaries to the effective permittivity of triglycine sulfate crystals in moderate low-and infralow-frequency fields, Phys. Sol State, Vol.43, No 1, pp. 1576-1579, ISSN 1063-7834

Stekhanova. Z. D.; Yatsenko, O. B.; Milovidova, S. D.; Sidorkin, A.S. \& Rogazinskaya, O. V. (2005). Properties of triglycine sulfate crystals grown from aqueous solutions, Appl Chem., Vol.78, No.1, pp. 42-49, ISSN 1070-4272 [Zh. Prikl. Khim.(St. Petersburg), Vol.78 (1), pp. 45]

Strukov, B. A. \& Levanyuk, A. P. (1998). Ferroelectric Phenomena in Crystals, Springer, ISBN 10354063121, Berlin.

Tagantsev, A. K., Cross, L. E. \& Fousek, J. (2010). Domains in Ferroic Crystals and Thin Films, Springer. ISBN 978-1-4419-1416-3, NY.

Wood, E.A. \& Holden, A.N. (1957). Monoclinic Glycine Sulfate: crystallographic data, Acta Crystallogr., Vol.10, pp. 145-146, ISSN 0108-2701 
Wurfel, P. \& Batra, I.P. (1973). Depolarization-field-induced instability in thin ferroelectric films - experiment and theory, Phys.Rev.B, Vol.8, No.11, pp. 5126-5133, ISSN 10980121

Wurfel, P.; Batra, I.P. \& Jacobs, J.T. (1973). Polarization instability in thin ferroelectric films, Phys.Rev.Lett., Vol.30, No.24, pp. 1218-1221, ISSN 0031-9007 


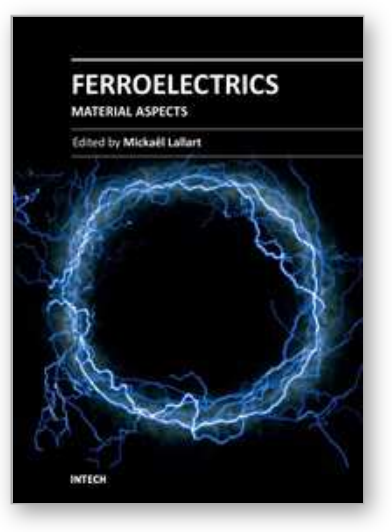

\author{
Ferroelectrics - Material Aspects \\ Edited by Dr. MickaÃ«I Lallart
}

ISBN 978-953-307-332-3

Hard cover, 518 pages

Publisher InTech

Published online 24, August, 2011

Published in print edition August, 2011

Ferroelectric materials have been and still are widely used in many applications, that have moved from sonar towards breakthrough technologies such as memories or optical devices. This book is a part of a four volume collection (covering material aspects, physical effects, characterization and modeling, and applications) and focuses on ways to obtain high-quality materials exhibiting large ferroelectric activity. The book covers the aspect of material synthesis and growth, doping and composites, lead-free devices, and thin film synthesis. The aim of this book is to provide an up-to-date review of recent scientific findings and recent advances in the field of ferroelectric materials, allowing a deep understanding of the material aspects of ferroelectricity.

\title{
How to reference
}

In order to correctly reference this scholarly work, feel free to copy and paste the following:

Balashova E.V. and Krichevtsov B.B. (2011). Amino-Acid Ferroelectric Thin Films, Ferroelectrics - Material Aspects, Dr. MickaÃ«I Lallart (Ed.), ISBN: 978-953-307-332-3, InTech, Available from:

http://www.intechopen.com/books/ferroelectrics-material-aspects/amino-acid-ferroelectric-thin-films

\section{INTECH}

open science | open minds

\section{InTech Europe}

University Campus STeP Ri

Slavka Krautzeka 83/A

51000 Rijeka, Croatia

Phone: +385 (51) 770447

Fax: +385 (51) 686166

www.intechopen.com

\section{InTech China}

Unit 405, Office Block, Hotel Equatorial Shanghai

No.65, Yan An Road (West), Shanghai, 200040, China

中国上海市延安西路65号上海国际贵都大饭店办公楼 405 单元

Phone: +86-21-62489820

Fax: +86-21-62489821 
(C) 2011 The Author(s). Licensee IntechOpen. This chapter is distributed under the terms of the Creative Commons Attribution-NonCommercialShareAlike-3.0 License, which permits use, distribution and reproduction for non-commercial purposes, provided the original is properly cited and derivative works building on this content are distributed under the same license. 